\title{
Understanding the Barrier and Mechanical Behavior of Different Nanofillers in Chitosan Films for Food Packaging
}

\author{
João Pires ${ }^{1, *(\mathbb{D}}$, Camila Damásio de Paula ${ }^{2}$, Victor Gomes Lauriano Souza ${ }^{1,3} \mathbb{D}^{\mathbb{D}}$, Ana Luísa Fernando ${ }^{1} \mathbb{D}$ \\ and Isabel Coelhoso $4, *$ (D)
}

1 MEtRICs, Departamento de Ciências e Tecnologia da Biomassa, NOVA School of Science and Technology I FCT NOVA, Campus de Caparica, Universidade NOVA de Lisboa, 2829-516 Caparica, Portugal; v.souza@campus.fct.unl.pt or victor.souza@inl.int (V.G.L.S.); ala@fct.unl.pt (A.L.F.)

2 Faculdade de Ciências Farmacêuticas, Universidade de São Paulo, Av. Prof. Lineu Prestes 580, CEP, São Paulo 05508-900, Brazil; camila.damasio@usp.br

3 International Iberian Nanotechnology Laboratory (INL), Av. Mestre José Veiga s/n, 4715-330 Braga, Portugal

4 LAQV-REQUIMTE, Departamento de Química, NOVA School of Science and Technology I FCT NOVA, Campus de Caparica, Universidade NOVA de Lisboa, 2829-516 Caparica, Portugal

* Correspondence: jr.pires@campus.fct.unl.pt (J.P.); imrc@fct.unl.pt (I.C.)

Citation: Pires, J.; Paula, C.D.d.; Souza, V.G.L.; Fernando, A.L.; Coelhoso, I. Understanding the Barrier and Mechanical Behavior of Different Nanofillers in Chitosan Films for Food Packaging. Polymers 2021, 13, 721. https://doi.org/ $10.3390 /$ polym 13050721

Academic Editor: Michelina Soccio

Received: 1 February 2021

Accepted: 23 February 2021

Published: 26 February 2021

Publisher's Note: MDPI stays neutral with regard to jurisdictional claims in published maps and institutional affiliations.

Copyright: (c) 2021 by the authors. Licensee MDPI, Basel, Switzerland. This article is an open access article distributed under the terms and conditions of the Creative Commons Attribution (CC BY) license (https:/ / creativecommons.org/licenses/by/ $4.0 /)$.

\begin{abstract}
The continuous petroleum-based plastics manufacturing generates disposal issues, spreading the problem of plastic pollution and its rise in the environment. Recently, innovative techniques and scientific research promoted biopolymers as the primary alternative for traditional plastics, raising and expanding global bioplastic production. Due to its unmatched biological and functional attributes, chitosan $(\mathrm{Ch})$ has been substantially explored and employed as a biopolymeric matrix. Nevertheless, the hydrophilicity and the weak mechanical properties associated with this biopolymer represent a significant intrinsic restriction to its implementation into some commercial applications, namely, in food packaging industries. Distinct methodologies have been utilized to upgrade the mechanical and barrier properties of $\mathrm{Ch}$, such as using organic or inorganic nanofillers, crosslinkers, or blends with other polymers. This review intends to analyze the most recent works that combine the action of different nanoparticle types with Ch films to reinforce their mechanical and barrier properties.
\end{abstract}

Keywords: biopolymer; mechanical properties; bionanocomposites; food packaging; oxygen permeability; water vapor permeability

\section{Introduction}

The food industry employs distinct types of materials in which glass and metal containers are highlighted for their excellent physical, gas, and water barrier properties, thus becoming important options to be considered by the food and beverage packaging. However, this type of materials have some negative aspects associated; they have increased transportation costs, demand excessive energy to recycle, and if not properly disposed of, may pose a risk to the environment because they do not decompose or decompose slowly in landfills or in the environment, releasing polluting substances [1]. Over the past century, plastic packaging has been increasingly replacing these traditional materials, due to their flexibility, variability in size and shape, thermal stability, and barrier properties. Despite all the appealing aspects undoubtedly connected to conventional plastic packaging, their non-renewable character, unsustainable use, and brief lifetime associated with their resistance to degradation caused a severe and realistic environmental problem, bringing out the responsibility to uncover creative and better ways to improve the disposal systems [2]. To fulfill the task of attenuating the ecological impact successfully and reduce the waste associated with the end of life of single-use plastics, novel bio-based food packaging systems should be intensely studied and optimized before being addressed 
for commercial purposes, ensuring that they are fully biodegradable and that no harmful toxicological and ecotoxicological effects arise from their use and disposal [3]. Bio-based plastics/polymers, recurrently expressed in literature as bioplastics or biopolymers, have recently been appointed as the logical candidates to replace conventional plastics due to their renewability, high abundance, accessibility, low cost, reduced toxicity, and biodegradable character [1]. The biopolymers normally used are polysaccharides (e.g., chitosan or pectin), lipids (e.g., natural waxes), proteins (e.g., whey protein), polyesters produced by microorganisms (e.g., polyhydroxybutyrate), synthesized from monomers (e.g., polylactic acid) or composites [4-9]. Chitin, a molecule derivative from glucose, is the second most plentiful natural polysaccharide found on our planet after cellulose and is mainly located in marine arthropods (i.e., more specifically in the exoskeleton of crustaceans) and in many other invertebrates, such as the cell walls of some fungi and algae. When submitting chitin to a fully or partially $\mathrm{N}$-deacetylation, the acetyl group $\left(-\mathrm{COCH}_{3}\right)$ from the amino group $\left(-\mathrm{NH}_{2}\right)$ at the $\mathrm{C}-2$ position is removed and a new bioactive polymer is designated as chitosan (Ch) arises. Structurally, $\mathrm{Ch}$ is a linear cationic polysaccharide with variable molecular weight (MW), assembled by D-glucosamine and N-acetyl-d-glucosamine units bonded by $\beta-1,4$ glycosidic linkages, with one amino $\left(\mathrm{NH}_{2}\right)$ group and two hydroxyl $(\mathrm{OH})$ groups in each repeating glycosidic units [10-12]. The ratio of D-glucosamine units to the sum of D-glucosamine and N-acetyl-d-glucosamine units that constitute the Ch chain is defined as the degree of deacetylation (DD). Pure $\mathrm{Ch}$ is insoluble in water, alkaline solutions, and even in organic solvents; however, when the DD reaches about $50 \%$, it becomes soluble in slightly acidic environments (below its $\mathrm{pKa} \sim 6.3$ ). As a result, $\mathrm{Ch}$ forms a highly versatile viscous solution after being dissolved due to the amino groups in the chain that protonate $\left(-\mathrm{NH}_{3}{ }^{+}\right)$, increasing intermolecular electric repulsions and resulting in a polycationic soluble polysaccharide, allowing it to activate reactive locations for a variety of new group attachments using mild reaction conditions [11,12]. Films and coatings, specifically made of chitosan and derivatives, have been extensively studied in the past decades for fresh and processed food conservation [13-15] because they possess the beneficial aspects inherently associated with polysaccharides. The combination of these properties with the advantageous film-forming feature and antimicrobial/antioxidant activity unlocks the door to the introduction of suitable chitosan active films and coatings on valuable scientific and technological markets such as food applications, but also pharmaceutical and biomedical applications [16].

A correct evaluation of the polymer barrier and mechanical properties is crucial to estimate the product-package shelf life and its maneuverability. The permeability through plastic materials depends on several factors, namely, (i) the permeant properties (molecule size and nature); (ii) material/polymer characteristics (molecular orientation, crystallinity, free volume, and chain stiffness); and (iii) external conditions (such as temperature and moisture) [17]. The temperature and humidity circumstances to which the food product will be exposed in the supply chain are vital for calculating the required barrier so that it applies to the conditions expected. Furthermore, the specific barrier requirement of a package system depends upon the food characteristics and the intended end-use applications [17-20]. The two main permeants studied in food packaging applications are water vapor and oxygen, because those gases can move from the internal or external environment through the polymer package wall, they result in possible negative changes in product quality and shelf-life and in the polymer itself. Moreover, the study of the permeability of oxygen $(\mathrm{OP})$ is important because the oxidation is related to the odor, color, taste, and deterioration of food; therefore, packages must provide a barrier to this gas $[18,21]$.

Petroleum-derived plastics often present a good water vapor barrier but poor oxygen block properties. On the contrary, the biopolymeric matrix (i.e., chitosan) is generally attractive due to its good obstacle characteristics against oxygen. In this subject, due to the well-ordered hydrogen-bonded network configuration, polysaccharides unveiled to be an effective barrier to gas transference, such as $\mathrm{O}_{2}$ and $\mathrm{CO}_{2}$, preventing oxidative rancidity, 
and surface-browning. In contrast, they typically own a hydrophilic nature resulting in poor water vapor and moisture barrier properties, which can turn into a dilemma in the preservation of perishable fresh-cut products [11,19-21]. Together with the barrier properties, mechanical properties (characterized by tensile strength, elastic modulus, elongation at break) also play an important role in the development of novel biodegradable plastic materials. When compared to plastics, bioplastics still present critical structural flaws coupled with processing challenges, which diminish their industrial applicability [22]. Blends of chitosan and anionic polymers could be a solution, showing improved mechanical and barrier properties when compared to chitosan films. This can be attributed to the formation of polyelectrolyte complexes through electrostatic interactions between the protonated amino groups of chitosan and the negatively charged side-chain assemblies of the other biopolymer. Better performance in terms of water vapor permeability and lower water solubility have been reported for combinations of chitosan with other polysaccharides, such as starch, pectin, or alginate compared to chitosan films [20].

To make it possible for biopolymer-based food packaging to go from concept to reality, it is fundamental to strengthen their composition, modifying and improving their properties. Therefore, another undergoing solution is the use of organic or inorganic nanoparticles to enhance the properties of the films, as was demonstrated in the study by Jamróz et al. [23]. The insertion of homogeneously dispersed nanoparticles, with a high aspect ratio and high surface area, into the biopolymer matrix is seen as a promising innovation, creating a novel functional class of materials, named bionanocomposites [2,11,24,25]. Polymer nanocomposites are mixtures of a certain polymer (or biopolymer) reinforced with small quantities of nanosized inorganic or organic (or bio-based organic) nanofillers with a particular size, geometry, and surface chemistry [26]. Nanotechnology represents the manipulation of matter with at least one dimension sized from 1 to 100 nanometers, and nanomaterials are characterized for having different physical, chemical, and biological properties than bulk material [18]. Thus, nanotechnology plays an important role as an alternative strategy to reinforce bio-based films through the incorporation of nanomaterials into the polymeric chain to enhance their mechanical and barrier properties [27]. After being reinforced with nanofillers, the chitosan-based nanocomposites are capable to be applied in various scientific areas and industries such as paper and food packaging, flexible electronics, sensing and biosensing, energy harvesting, liquid crystals, biomedicine and cosmetics, catalysis, adsorption, separation, decontamination, or filtration systems [28-33].

This review's main focus is to explore and summarize the latest results on how different nanofillers interact with chitosan in order to enhance the film's barrier and mechanical properties to be used efficiently in food packaging systems. Critical analysis of the most recent information available will be useful to identify future opportunities for the use of nanoparticles in food packaging systems, helping to overcome current restrictions associated with the limited scale-up of chitosan-based polymers in food packaging.

\section{Nanotechnology as Reinforcement}

\subsection{Barrier Properties}

The incorporation of nano-sized particles is under intense investigation for enhancement of barrier properties of packaging. The barrier properties of polymers can be significantly altered by the inclusion of inorganic platelets with a high aspect ratio to alter the diffusion path of gas molecules. Various models have been proposed to predict the permeability of platelet-filled composites as listed in Table 1. These models are generally based on random, parallel platelets perpendicular to the permeation direction (random in only two directions). At a high aspect ratio, significant decreases in permeability are predicted and observed in practice [34]. 
Table 1. Prediction models for barrier properties of nanocomposites (adapted from [34]).

\begin{tabular}{|c|c|c|c|}
\hline Model & Filler Type & Aspect Ratio $(\alpha)$ & Formula \\
\hline Nielsen & Ribbon & $\begin{array}{c}\alpha=w / t \text { (length is infinite, } w \text { is the width, } \\
t \text { is the thickness) }\end{array}$ & $(\mathrm{P} 0 / \mathrm{P})(1-\phi)=1+\alpha \phi / 2$ \\
\hline $\begin{array}{c}\text { Cussler } \\
\text { (regular array) }\end{array}$ & Ribbon & $\begin{array}{c}\alpha=w / t \text { (length is infinite, } w \text { is the width, } \\
t \text { is the thickness) }\end{array}$ & $(\mathrm{P} 0 / \mathrm{P})(1-\phi)=1+(\alpha \phi) 2 / 4$ \\
\hline $\begin{array}{c}\text { Cussler } \\
\text { (random array) }\end{array}$ & Ribbon & $\begin{array}{c}\alpha=w / t \text { (length is infinite, } w \text { is the width, } \\
t \text { is the thickness) }\end{array}$ & $(\mathrm{P} 0 / \mathrm{P})(1-\phi)=(1+\alpha \phi / 3) 2$ \\
\hline Gusev and Lusti & Disk & $\begin{array}{c}\alpha=\mathrm{d} / \mathrm{t} \text { (circular shape, } \mathrm{d} \text { is the diameter, } \mathrm{t} \\
\text { is the thickness) }\end{array}$ & $(\mathrm{P} 0 / \mathrm{P})(1-\phi)=\exp [(\alpha \phi / 3.47) 0.71]$ \\
\hline Fredrickson and Bicerano & Disk & $\begin{array}{c}\alpha=\mathrm{d} / \mathrm{t} \text { (circular shape, } \mathrm{d} \text { is the diameter, } \mathrm{t} \\
\text { is the thickness) }\end{array}$ & $\begin{array}{c}(\mathrm{P} 0 / \mathrm{P})(1-\phi)=4(1+\mathrm{x}+0.1245 \mathrm{x} 2) /(2+\mathrm{x}) 2 \\
\text { where } \mathrm{x}=\alpha \phi / 2 \ln (\alpha / 2)\end{array}$ \\
\hline Bharadwaj & Disk & $\begin{array}{c}\alpha=\mathrm{d} / \mathrm{t} \text { (circular shape, } \mathrm{d} \text { is the diameter, } \mathrm{t} \\
\text { is the thickness) }\end{array}$ & $\begin{array}{l}(\mathrm{P} 0 / \mathrm{P})(1-\phi)=1+0.667 \alpha \phi(\mathrm{S}+0.5), \text { where } \mathrm{S} \text { is } \\
\text { the orientation factor from }-0.5 \text { to } 1 .\end{array}$ \\
\hline
\end{tabular}

P-permeability of composites; P0—permeability of pure polymer; $\phi$-volume fraction.

Common fillers used to prepare nanocomposites for food packaging applications are nanoclays, cellulose nanofibers and nanocrystals, carbon nanotubes, and metal oxides. Tables 2-4 show the effect of different nanofillers and compositions on water vapor permeability (WVP) and oxygen permeability (OP) through chitosan nanocomposite films.

The amount of nanofillers ranges between $0.5 \%(w / w)$ and $10 \% w / w$ of chitosan, except in a few cases in which concentrations are up to $30 \%(w / w)$. It can also be seen that most studies present only WVP results. Although OP is an important parameter because it will influence the oxidation of the food products and consequently, the product shelf life is seldom reported [35].

In most studies, a decrease of permeability with the increase of filler amount may be observed. This is due to the increase in the diffusion path that slows the permeation of gases through the polymer barrier. In some, this trend happens until a critical nanoparticle content, after which a constant or a small increase of permeability is detected. This behavior has been explained with deficient nanoparticles' exfoliation or a decrease in aspect ratio. Moreover, when inorganic particles are included in a polymer matrix, their effect on the composite permeability is related to the type of interaction of the particles with the permeant species, and with the polymer and the resulting internal morphology. For instance, regarding the barrier to water vapor, the water adsorbs to the polymer and hydrophilic nanoparticles. The swelling of both solids may create unfilled zones around the particles where water vapor diffusion will be made easier and higher. From a given particle content, the increase in the diffusion path due to the impermeable barrier is nullified by the contribution of these unfilled diffusion zones, leading to stability or even an increase in permeability [17].

The barrier properties of chitosan films with different nanofillers are presented and discussed in the following subchapters.

\subsubsection{Nanoclays}

Montmorillonite (MMT) is a hydrated, alumina-silicate layered clay, and its negative charge is balanced with exchangeable cations, as $\mathrm{Na}^{+}$and $\mathrm{Ca}^{2+}$. It is one of the most used clays because of its low cost, high active surface, and its capacity to improve the mechanical and barrier properties of chitosan nanocomposites [11]. The use of nanoclays in films has several advantages due to its low cost, availability, and good surface area. The addition of montmorillonite gives the films a lighter composition and less risk of microbial contamination, for the packaging and for the food packaged by this film, improving the shelf life of the food packaged [36]. Regarding toxicity, the MMT does not appear to be toxic and can be used widely in the food industry [37].

Nanoclays can provide the enhancement of the water barrier properties of bio-based films by the increase on the tortuous path of the water vapor molecules through the 
polymeric chain [38]. Exfoliated structures, in comparison with the intercalated and micro-phase separated structures, are more efficient to prevent the film from being waterpermeable $[11,38]$. Because the permeability to water vapor is related to the deterioration of food, films intended to be in direct contact with food must have a good barrier to this water vapor [21]. Some examples of reinforced chitosan films with MMT or halloysite nanotubes (HNT) are shown in Table 2 and described below.

Table 2. Barrier properties of chitosan films reinforced with nanoclays.

\begin{tabular}{|c|c|c|c|c|}
\hline Formulation & Incorporation Method & $\begin{array}{c}\text { Water Vapor Permeability } \\
\text { (Percentage Relatively to Control) }\end{array}$ & $\begin{array}{l}\text { Oxygen Permeability (Percentage } \\
\text { Relatively to Control) }\end{array}$ & Ref \\
\hline $\begin{array}{c}2 \%(w / v) \text { Ch (deacetylation } \\
\text { degree of } 75-85 \%) ; \text { Glycerol } \\
25 \%(w / w C h)\end{array}$ & $\begin{array}{l}\text { Mechanical stirring and } \\
\text { ultrasonic homogenizer }\end{array}$ & $\begin{array}{l}\text { Ch + 1\% MMTNa: Decreased 31\% } \\
\text { Ch + 3\% MMTNa: Decreased 56\% } \\
\text { Ch }+5 \% \text { MMTNa: Decreased 38\% }\end{array}$ & Not Performed & [39] \\
\hline $\begin{array}{c}1.5 \%(w / v) \mathrm{Ch} \text { (deacetylation } \\
\text { degree of } 75 \%) ; \text { Glycerol } 30 \% \\
(w / w \mathrm{Ch})\end{array}$ & $\begin{array}{l}\text { Rotor-stator homogenizer } \\
\text { (Ultra-Turrax) and ultrasonic } \\
\text { homogenizer }\end{array}$ & $\mathrm{Ch}+2.5 \% \mathrm{MMTNa}:$ Increased 25\% & $\mathrm{Ch}+2.5 \%$ MMTNa: Decreased 47\% & [25] \\
\hline $\begin{array}{c}1 \%(w / v) \text { Ch (deacetylation } \\
\text { degree of about } 75 \%) \\
\text { Glycerol } 40 \%(w / w \mathrm{Ch})\end{array}$ & $\begin{array}{l}\text { Mechanical stirring and } \\
\text { ultrasonic homogenizer }\end{array}$ & $\begin{array}{l}\text { Ch }+5 \% \text { HNT: Decreased } 2 \% \\
\text { Ch }+10 \% \text { HNT: Decreased } 5 \% \\
\text { Ch }+15 \% \text { HNT: Decreased 10\% } \\
\text { Ch }+20 \% \text { HNT: Decreased } 13 \% \\
\text { Ch }+25 \% \text { HNT: Decreased } 14 \% \\
\text { Ch }+30 \% \text { HNT: Decreased } 16 \%\end{array}$ & Not Performed & [40] \\
\hline $\begin{array}{l}2 \%(w / v) \text { Ch (deacetylation } \\
\text { degree greater than } 75 \%) \\
\text { Glycerol } 25 \%(w / w C h)\end{array}$ & $\begin{array}{l}\text { Mechanical stirring and } \\
\text { ultrasonic probes }\end{array}$ & $\begin{array}{c}\text { Ch + 1\% MMT: Decreased 28\% } \\
\text { Ch + 3\% MMT: Decreased 37\% } \\
\text { Ch + 5\% MMT: Decreased 17\% } \\
\text { Ch + 1\% MMTCuO-20: Decreased 26\% } \\
\text { Ch + 3\% MMTCuO-20: Decreased 39\% } \\
\text { Ch + 5\% MMTCuO-20: Decreased 35\% } \\
\text { Ch + 1\% MMTCuO-90: Decreased 72\% } \\
\text { Ch + 3\% MMTCuO-90: Decreased 77\% } \\
\text { Ch + 5\% MMTCuO-90: Decreased 76\% }\end{array}$ & $\begin{array}{c}\text { Ch + 1\%MMT: Decreased 12\% } \\
\text { Ch + 3\%MMT: Decreased 55\% } \\
\text { Ch +5\%MMT: Decreased 37\% } \\
\text { Ch + 1\%MMTCuO-20: Decreased 31\% } \\
\text { Ch + 3\%MMTCuO-20: Decreased } 60 \% \\
\text { Ch + 5\%MMTCuO-20: Decreased } 49 \% \\
\text { Ch + 1\%MMTCuO-90: Decreased } 47 \% \\
\text { Ch + 3\%MMTCuO-90: Decreased } 79 \% \\
\text { Ch + 5\%MMTCuO-90: Decreased } 55 \%\end{array}$ & [41] \\
\hline $\begin{array}{l}1 \%(w / w) \text { Ch (deacetylation } \\
\text { degree greater than } 85 \%) ; \\
\text { Glycerol } 30 \%(w / w C h) \text { of } \\
\text { chitosan }\end{array}$ & $\begin{array}{l}\text { Nanoparticles were } \\
\text { dispersed stirred at } 400 \\
\text { rotational frequency and } \\
\text { immersed in an } \\
\text { ultrasound bath }\end{array}$ & $\begin{array}{l}\text { Ch }+0.5 \% \text { MMT: Increased 16\% } \\
\text { Ch }+1 \% \text { MMT: Decreased 19\% }\end{array}$ & $\begin{array}{l}\mathrm{Ch}+0.5 \% \text { MMT: Increased } 89 \% \\
\mathrm{Ch}+1 \% \text { MMT: Increased } 225 \%\end{array}$ & [42] \\
\hline $\begin{array}{l}3 \%(v / v) \text { Ch (deacetylation } \\
\text { degree of about } 95 \%) ; \\
\text { Polycaprolactone } 12 \%(w / w \\
\text { Ch) }\end{array}$ & $\begin{array}{l}\text { Mechanical stirring and } \\
\text { ultrasonic homogenizer }\end{array}$ & $\begin{array}{l}\mathrm{Ch}+2 \% \text { HNT: Decreased } 15 \% \\
\mathrm{Ch}+4 \% \text { HNT: Decreased } 23 \% \\
\mathrm{Ch}+6 \% \text { HNT: Decreased } 25 \%\end{array}$ & Not Performed & [43] \\
\hline $\begin{array}{c}1.5 \%(w / w) \mathrm{Ch} \\
\text { (deacetylation degree of } \\
\text { about } 90 \%)\end{array}$ & $\begin{array}{l}\text { Mechanical stirring and } \\
\text { ultrasonic homogenizer }\end{array}$ & $\begin{array}{c}\text { Ch + 0.5\% MMTNa: Decreased 2.7\% } \\
\text { Ch + 1\% MMTNa: Decreased } 7.4 \% \\
\text { Ch }+2 \% \text { MMTNa: Decreased } 4.0 \%\end{array}$ & $\begin{array}{c}\text { Ch }+0.5 \% \text { MMTNa: Decreased } 32 \% \\
\text { Ch }+1 \% \text { MMTNa: Decreased } 61 \% \\
\text { Ch }+2 \% \text { MMTNa: Decreased } 51 \%\end{array}$ & [37] \\
\hline $\begin{array}{l}0.2 \%(v / v) \text { Ch (deacetylation } \\
\text { degree of about } 75 \%) ; \\
\text { carboxymethyl cellulose } 1 \% \\
(w / w \mathrm{Ch})\end{array}$ & Mechanical stirring & $\begin{array}{l}\text { Ch }+5 \% \text { HNT: Decreased } 60 \% \\
\text { Ch }+7 \% \text { HNT: Decreased } 71 \% \\
\text { Ch }+10 \% \text { HNT: Decreased } 75 \%\end{array}$ & Not Performed & [44] \\
\hline $\begin{array}{l}2 \%(w / w) \text { Ch (deacetylation } \\
\text { degree of about } 90 \%)\end{array}$ & Mechanical stirring & $\begin{array}{l}\text { Ch }+25 \% \text { HNT: Decreased } 6,1 \% \\
\text { Ch }+42 \% \text { HNT: Decreased } 15 \% \\
\text { Ch }+66 \% \text { HNT: Decreased } 29 \% \\
\text { Ch }+100 \% \text { HNT: Decreased } 20 \%\end{array}$ & Not Performed & [45] \\
\hline
\end{tabular}

Ch—chitosan; MMTNa—sodium montmorillonite; HNT—halloysite nanotubes; MMTCuO-montmorillonite with copper (II) oxide.

Films prepared with $1 \%(w / v \mathrm{Ch}), 30 \%$ glycerol, and two different MMT at $0.5(w / w)$ and $1 \%(w / w \mathrm{Ch})$, demonstrated a decrease in WVP proportionally to the amount of MMT added in the matrix (Table 2) [19]. According to Llanos et al. (2018) [42], this phenomenon occurred due to the tortuous path provided by the MMT nanoparticles that are dispersed in the chitosan matrix, which makes the water vapor more difficult to diffuse through the film. The WPV was determined using the gravimetric method. This study also evaluated the material's oxygen permeability and the presence of nanoclay. Contrary to what was expected, the OP increased, because the nanoparticles (NPs) increased the porosity of the film, changing its microstructure [42]. The addition of MMT can improve the barrier properties of films; however, this nanoclay generally does not enhance the antimicrobial properties of chitosan films. Thus, it can be interesting to add antimicrobial agents, such as metal oxide nanoparticles or essential oils, to confer this antimicrobial activity to the packaging [11]. Copper oxide nanoparticles are known for their antimicrobial activity; however, the release of copper ions toward the food can cause leaching, enhance the food 
deterioration process, and pose some toxicity. Thus, the combination with MMT with exchangeable positively charged ions, such as $\mathrm{Na}^{+}$or $\mathrm{Ca}^{2+}$, can prevent copper ions from being released [41].

Bionanocomposites based on chitosan $(2 \% w / v)$ were formulated with the addition of $25 \%(w / w \mathrm{Ch})$ of glycerol and three different MMT concentrations $(1 \%, 3 \%$, and $5 \% w / w$ $\mathrm{Ch}$ ) with or without $\mathrm{CuO}$ NPs. Two complexes were studied MMTCuO-20 and MMTCuO90 (produced differently regarding the synthesizing time inside the muffle furnace, $20 \mathrm{~min}$ or $90 \mathrm{~min}$, respectively) [41]. In this case, the WPV study was also conducted by the gravimetric method and the OP study by the ASTM D3985-05 [46] method. Overall, the addition of pure nanoclay decreased the WVP in all treatments; however, the lowest result was achieved with the addition of $3 \%$ of MMT (a decrease of $37 \%$ in comparison to the control sample). At the level of 5\% MMT, the WPV was slightly superior to the composites with $3 \%$, which was related to the possible agglomeration of the NPs. When the complex with MMT and CuO NPs were used, the same pattern was observed; however, $\mathrm{CuO}$ NPs were able to reduce even more the material WPV (reaching $77 \%$ reduction), and MMTCuO-90 at 3\% was the best formulation. These results were attributed to the presence of hydrogen interactions between chitosan, glycerol, and an MMT-CuO, which decreased the number of hydroxyl groups in the film to react with the water, and the building of a tortuous path, that makes the diffusion of water vapor difficult [41]. Concerning OP, the addition of MMT to the matrix formed by chitosan and glycerol also reduced the oxygen permeability. The best result was also with the addition of MMT-CuO because the groups present in chitosan have a strong attraction with MMT-CuO, which closes the net of the film, preventing the entry of oxygen [41].

Contradictory behavior is also found in literature, as in Souza et al. (2019) [25] and Xu et al. (2018) [37], which did not observe a statistical difference in the WVP of chitosan films incorporated with different amounts of MMT (varying from $0.5-2.5 \% w / w \mathrm{Ch}$ ). However, the OP in both studies was reduced around $32-61 \%$ in comparison to pristine chitosan film. As described before, it seems that when the amount of MMT incorporated is increased the enhancement ability diminishes, probably due to the agglomeration effect. In addition, within the formulations assessed, the incorporation of $1 \%$ of MMT was demonstrated to be the best reinforcement formula $[25,37]$.

Halloysite nanotubes ( $\mathrm{HNTs}$ ), $\mathrm{Al}_{2} \mathrm{Si}_{2} \mathrm{O}_{5}(\mathrm{OH})_{4} \cdot \mathrm{nH}_{2} \mathrm{O}$, belongs to a subgroup of kaolin clay, which is generally recognized as a safe (GRAS) food packaging material due to its non-toxicity and biocompatibility [40]. HNTs show a nanotubular morphology, with an outer tube diameter of nanometric dimension, whereas the length can range typically from hundreds of nanometers to about $1.5 \mu \mathrm{m}$ [40]. Some of the advantages of HNTs are their hydrophilic characteristic, high dispersibility (easily exfoliated because of its structure with high aspect ratio), thermal stability, and non-toxicity [40,47].

In vitro and in vivo studies with HNTs demonstrated their biocompatibility with tissues and cells, thus showing that they are also interesting options for film production. In the formulation was added $0.2 \%$ of chitosan, carboxymethyl cellulose (CMX) in the proportion of 1:2 to chitosan and HNT in three different concentrations, $5 \%, 7.5 \%$, and $10 \%(w / w C h)$ [44]. The authors concluded that with the addition of HNT, the chitosan and CMX films have a greater barrier to water vapor due to the dispersion of the nanoclay in the mixture. This phenomenon was attributed to the more tortuous paths due to the hydrophilic interaction between chitosan and HNT, which also caused the reduction of the hydrophilic parts, thus making the interaction with water vapor more difficult and, consequently, the diffusion process more difficult to occur [44].

\subsubsection{Cellulosic Nanofibers and Nanocrystals}

Nanocellulose (NC), either as nanofibers or nanocrystals, are also nanomaterials commonly used to strengthen bio-based films by the improvement on their mechanical properties and the reduction on the WVP and OP [48], which are the main drawbacks of biopolymers' application in the packaging industry [27]. They are an environmentally 
friendly nanofiller that can be highlighted due to their biodegradability, low density, nontoxicity, excellent mechanical properties, and high aspect ratio that guarantee a huge interface with the polymeric matrix [49-51].

As previously described for the nanoclays, the decrease in the WVP or OP is generally attributed to the tortuosity created by, among other factors, the incorporation of nanocellulose, and this reinforcement is a topic that merits further research attention [52]. The types of nanocellulose used for this purpose vary from the source, namely, bacterial or extracted from biomass, and configuration (in crystals or fibers). The content of NC used in the film is generally low, between $0-35 \%$ ( $w / w$ of polymer), as described in Table 3.

Table 3. Barrier properties of chitosan films reinforced with cellulose nanoparticles.

\begin{tabular}{|c|c|c|c|c|}
\hline Formulation & Incorporation Method & $\begin{array}{c}\text { Water Vapor Permeability } \\
\text { (Percentage Relatively to Control) }\end{array}$ & $\begin{array}{c}\text { Oxygen Permeability (Percentage } \\
\text { Relatively to Control) }\end{array}$ & Ref \\
\hline $\begin{array}{c}2 \%(w / v) \mathrm{Ch} \\
\text { (deacetylation degree not } \\
\text { specified) }\end{array}$ & $\begin{array}{l}\text { Mechanical stirring and } \\
\text { ultrasonic homogenizer }\end{array}$ & $\begin{array}{l}\text { Ch }+1 \% \text { CNC: }: \text { Decreased } 34 \% \\
\text { Ch }+3 \% \text { CNC: Decreased 16\% } \\
\text { Ch }+5 \% \text { CNC: Decreased } 38 \% \\
\text { Ch }+10 \% \text { CNC: Decreased } 25 \%\end{array}$ & Not Performed & [53] \\
\hline $\begin{array}{c}1 \%(w / v) \mathrm{Ch} \\
\text { (deacetylation degree of } \\
90 \%)\end{array}$ & $\begin{array}{l}\text { Mechanical stirring and } \\
\text { ultrasonic homogenizer }\end{array}$ & $\begin{array}{l}\text { Ch }+2 \% \text { CNC: Decreased } 24 \% \\
\text { Ch }+4 \% \text { CNC: Decreased } 29 \% \\
\text { Ch }+6 \% \text { CNC: Decreased } 34 \% \\
\text { Ch }+8 \% \text { CNC: Decreased } 37 \%\end{array}$ & Not Performed & [54] \\
\hline $\begin{array}{l}3 \%(w / v) \text { Ch (degree of } \\
\text { deacetylation } 94 \%)\end{array}$ & Mechanical stirring & $\begin{array}{l}\text { Ch }+10 \% \text { CNC: }: \text { Decreased } 32 \% \\
C h+20 \% \text { CNC: Decreased 28\% }\end{array}$ & Not Performed & [55] \\
\hline $\begin{array}{c}2 \%(w / v) \mathrm{Ch} \\
\text { (deacetylation degree not } \\
\text { specified) }\end{array}$ & Mechanical stirring & $\begin{array}{l}\text { Ch }+10 \% \text { CGTOCNF: Decreased } 6 \% \\
\text { Ch }+17 \% \text { CGTOCNF: Increased } 2 \% \\
\text { Ch }+25 \% \text { CGTOCNF: Decreased } 4 \% \\
\text { Ch }+33 \% \text { CGTOCNF: Decreased } 7 \%\end{array}$ & $\begin{array}{l}\text { Ch }+10 \% \text { CGTOCNF: Increased 13\% } \\
\text { Ch }+17 \% \text { CGTOCNF: Increased 16\% } \\
\text { Ch }+25 \% \text { CGTOCNF: Increased } 3 \% \\
\text { Ch }+33 \% \text { CGTOCNF: Increased } 62 \%\end{array}$ & [56] \\
\hline $\begin{array}{c}1 \%(w / v) \mathrm{Ch} \\
\text { (deacetylation degree } \\
75-85 \%)\end{array}$ & $\begin{array}{l}\text { Nanoparticles were } \\
\text { dispersed with the aid of } \\
\text { mechanical stirring }\end{array}$ & $\begin{array}{l}\text { Ch }+2 \% \text { BCNC: Decreased } 9 \% \\
C h+4 \% \text { BCNC: Decreased } 20 \% \\
C h+6 \% \text { BCNC: Decreased } 27 \%\end{array}$ & Not Performed & [57] \\
\hline
\end{tabular}

Ch—chitosan; CNC—cellulose nanocrystals; CGTOCNF_curcumin-grafted; BCNC—bacterial nanocellulose.

The trend observed is that despite the type or source of NC used, WVP reduces with the incorporation of nanocellulose particles until a maximum (in general below $10 \% w / w$ ), from which with the increase of the amount incorporated the barrier properties reduces. In the study of Corsello et al. (2017) [53], bionanocomposites based on chitosan incorporated with cellulose nanocrystals (CNC) at four increasing levels $(1 \%, 3 \%, 5 \%$, and $10 \% w / w$ Ch) showed a reduction in the WVP up to $38 \%$ in comparison to pristine chitosan films. The minimum permeability to water vapor was observed with the amount of $5 \% \mathrm{CNC}$, and when $10 \%$ was incorporated, the WVP decreased to $25 \%$. The author attributed the WVP reduction to the presence of NC, which increased the tortuosity in the polymer matrix films, leading to slower water vapor diffusion processes [53,55]. In contrast, excessive NC destroyed the polymeric network structure of chitosan, allowing for the formation of gaps for water vapor molecules to pass through [56].

Other factors might account for this reduction in the WVP, such as (i) the increase in the polymer's crystallinity (acting as crystalline fillers that increases the distance for the molecules of water to pass through, i.e., a more tortuous path); (ii) the improvement on the film uniformity, and iii) making the film tough enough to decrease the frequency of cracks or other defects that could lead to a high gas permeability [52,56].

The study of OP is scarce, and few studies investigate it simultaneously with WVP, as in the study of Zhang et al. (2021) [56]. The author proposed a novel bionanocomposite of chitosan reinforced with curcumin grafted TEMPO-oxidized cellulose nanofibers (CGTOCNF) at 10\%, 17\%, 25\%, and 33\% ( $w / w$ Ch). Regarding WVP, similar behavior was reported, with a reduction in WVP with CGTOCNF incorporation. On the other hand, OP of the bionanocomposites increased with the incorporation of the nanoparticle complex; thus, the addition of CGTOCNF had a more powerful destructive effect than 
improved crystallinity for the polymer network, and the hydrophobicity of CGTOCNF was not sufficient to counterbalance this, contributing less to the oxygen barrier [56].

Table 4. Barrier properties of chitosan films reinforced with metal oxide nanoparticles and carbon nanotubes.

\begin{tabular}{|c|c|c|c|c|}
\hline Formulation & Incorporation Method & $\begin{array}{c}\text { Water Vapor Permeability (Percentage } \\
\text { Relatively to Control) }\end{array}$ & $\begin{array}{l}\text { Oxygen Permeability (Percentage } \\
\text { Relatively to Control) }\end{array}$ & Ref \\
\hline $\begin{array}{c}1 \%(w / v) \mathrm{Ch} ; 2 \%(w / v) \\
\text { purified CNT in } \\
\text { dimethylformamide; } 6 \\
\text { different PLA/CNT /Ch } \\
\text { concentrations }(0,1,3,5,7 \\
9 \% \mathrm{Ch})\end{array}$ & $\begin{array}{l}\text { Nanotubes were } \\
\text { dispersed with stirring } \\
\text { and electrospinning }\end{array}$ & $\begin{array}{l}\text { PLA/CNTs/Ch-1\%: Decreased 30\% } \\
\text { PLA/CNTs/Ch-3\%: Decreased } 64 \% \\
\text { PLA/CNTs/Ch-5\%: Decreased } 71 \% \\
\text { PLA/CNTs/Ch-7\%: Decreased 75\% } \\
\text { PLA/CNTs/Ch-9\%: Decreased } 54 \%\end{array}$ & Not performed & [58] \\
\hline $\begin{array}{l}1 \mathrm{~g} \text { of } \mathrm{Ch} \text { in the } 1 \% \text { acetic } \\
\text { acid solution; }\end{array}$ & $\begin{array}{l}\text { Metal oxides were } \\
\text { sonicated to be } \\
\text { dispersed }\end{array}$ & $\begin{array}{l}\text { Ch }+0.1 \% \text { ZnONP: Decreased } 21 \% \\
\text { Ch }+0.3 \% \text { ZnONP: Decreased 31\% } \\
\text { Ch }+0.5 \% \text { ZnONP: Decreased } 56 \%\end{array}$ & Not performed & [59] \\
\hline $2 \%(w / v) \mathrm{Ch}$ & $\begin{array}{c}\text { Metal oxides were } \\
\text { dispersed with stirring }\end{array}$ & $\begin{array}{l}\text { Ch + 30ZnO: Decreased } 66 \% \\
\text { Ch + 50ZnO: Decreased 77\% } \\
\text { Ch + 70ZnO: Decreased } 87 \%\end{array}$ & $\begin{array}{l}\mathrm{Ch}+30 \mathrm{ZnO}: \text { Decreased } 7.5 \% \\
\mathrm{Ch}+50 \mathrm{ZnO}: \text { Decreased } 10 \% \\
\mathrm{Ch}+70 \mathrm{ZnO}: \text { Decreased } 41 \%\end{array}$ & [60] \\
\hline $\begin{array}{l}0.5 \%(w / v) \mathrm{Ch} ; 1 \% \text { cellulose } \\
\text { acetate (CelAc) solution; } \\
0.25 \% \text { glycerol }\end{array}$ & $\begin{array}{l}\text { Metal oxides were } \\
\text { dispersed in formic acid } \\
\text { and after were mixed } \\
\text { with the polymer } \\
\text { solution }\end{array}$ & $\begin{array}{l}\mathrm{Ch}-\mathrm{CelAc}-\mathrm{CeO}_{2}-0.1 \% \text { : Increased } 36 \% \\
\mathrm{Ch}-\mathrm{CelAc}-\mathrm{CeO}_{2}-1 \% \text { : Increased } 157 \%\end{array}$ & Not performed & [61] \\
\hline $\begin{array}{c}\text { Ch }(0.2 \mathrm{~g}) \text { was dispersed in } \\
50.0 \mathrm{~mL} \text { acidic water }(0.5 \% \\
v / v \text { acetic acid }\end{array}$ & $\begin{array}{l}\text { Metal oxides were } \\
\text { dispersed in water and } \\
\text { sonicated in an } \\
\text { ultrasonic bath }\end{array}$ & $\begin{array}{l}\text { CMC-Ch-OL-ZnONPs 0.5\%: Increased 5.1\% } \\
\text { CMC-Ch-OL-ZnONPs 1\%: Increased 20\% } \\
\text { CMC-Ch-OL-ZnONPs 2\%: Increased 28\% }\end{array}$ & Not performed & [14] \\
\hline $\begin{array}{l}1.5 \%(w / v) \text { Ch in a } 1 \%(v / v) \\
1-(\beta)-l \text { actic acid; } 0.5 \% \\
\text { glycerol }(w / v) ; 3 \text { different } \\
\text { acetylene flux }(4 \mathrm{sccm}, 12 \\
\text { sccm, } 20 \mathrm{sccm})\end{array}$ & $\begin{array}{l}\text { Carbon-based coatings } \\
\text { were dispersed with } \\
\text { radio-frequency reactive } \\
\text { magnetron sputtering }\end{array}$ & $\begin{array}{l}\text { Ch-Acetylene } 4 \text { sccm: Increased } 34 \% \\
\text { Ch-Acetylene } 4 \text { sccm: Increased } 12 \% \\
\text { Ch-Acetylene } 4 \text { sccm: Increased } 11 \%\end{array}$ & $\begin{array}{l}\text { Ch-Acetylene } 4 \text { sccm: Increased 14\% } \\
\text { Ch-Acetylene } 12 \text { sccm: Decreased } 42 \% \\
\text { Ch-Acetylene } 20 \text { sccm: Decreased 81\% }\end{array}$ & [62] \\
\hline $\begin{array}{c}1 \%(w / v) \mathrm{Ch} ; 20 \% \text { glycerol } \\
(w / v \mathrm{Ch})\end{array}$ & $\begin{array}{l}\text { Metal oxides } \\
\text { weredispersed with } \\
\text { refluxed }\end{array}$ & $\begin{array}{l}\text { ChG7ZnO: Decreased } 81 \% \\
\text { (The other results are not showed) }\end{array}$ & Not performed & [63] \\
\hline $\begin{array}{c}0.6 \%(w / v) \text { Ch; } 4 \text { different } \\
\text { ZnONP concentrations } \\
(0.165,0.33,0.66,0.99 \mathrm{~g} \text { in } 15 \\
\text { mL Water })\end{array}$ & $\begin{array}{l}\text { Metal oxides were } \\
\text { dispersed with vigorous } \\
\text { stirring }\end{array}$ & $\begin{array}{l}\mathrm{Ch} / \mathrm{ZnO} 0.165 \text { g: Decreased } 13 \% \\
\mathrm{Ch} / \mathrm{ZnO} 0.33 \text { g: Decreased } 17 \% \\
\mathrm{Ch} / \mathrm{ZnO} 0.66 \text { g: Decreased } 8.0 \% \\
\mathrm{Ch} / \mathrm{ZnO} 0.99 \text { g: Decreased } 6.8 \%\end{array}$ & Not performed & [64] \\
\hline $\begin{array}{l}1 \%(w / v) \text { Ch and } 1 \%(w / w \\
\text { of Ch) of } \mathrm{MgO} \mathrm{NP}\end{array}$ & $\begin{array}{l}\text { Metal oxides } \\
\text { weredispersed with } \\
\text { vigorous stirring }\end{array}$ & Decreased 53\% & Not performed & [65] \\
\hline
\end{tabular}

$\mathrm{Ch}$-chitosan; PLA—polylactic acid; $\mathrm{CNTs}$ - carbon nanotubes; $\mathrm{ZnO}$ - zinc Oxide; CelAc—cellulose acetate; $\mathrm{CeO}_{2}$ —cerium (IV) oxide; CMC—-arboxymethylcellulose; OL-oleic acid.

\subsubsection{Metal Oxides Nanoparticles and Carbon Nanotubes}

Metal oxide nanoparticles and carbon nanotubes are other classes of NPs that can be used to improve the quality of the films in relation to their oxygen and water vapor barrier properties. Some examples of the latest studies on this matter are shown in Table 4.

According to the study by Sanuja et al. (2015) [59], who evaluated the WVP of chitosan films incorporated with three different concentrations of zinc oxide nanoparticles (ZnONP) $(0.1 \% ; 0.3 \%$, and $0.5 \%)$, there is a decrease in the material's WVP with the increment of the NP concentration in the formulation (up to $56 \%$ lower than pristine chitosan films). This behavior was attributed to the fact that chitosan has high hydrophilic properties, so it is easier to interact with the hydrogen in the water molecule, and with the addition of $\mathrm{ZnO} N P s$, its dispersion in the matrix forms a more efficient barrier to contain the water vapor permeability. In this experiment, neem essential oil was also added to the chitosan formulation with $0.5 \% \mathrm{ZnO}$ NPs. Because it presents even more hydrophobic characteristics and interacts with chitosan, it reduced WVP even further [59].

The use of ZnO NPs is very efficient to increase the antimicrobial properties of the film and its barrier properties, including WVP and OP, and that is the reason many studies with the reinforcement of chitosan with this NP are found in the literature. Moreover, $\mathrm{ZnO}$ NPs have antioxidant properties and are non-toxic when added to the film, being recognized as GRAS by the US Department of Food and Drug Administration (FDA). 
Chitosan films with ZnO NPs and gallic acid allowed the reduction of WVP in relation to the pure chitosan film, according to the study published by Yadav et al. (2021) [60]. This occurred due to the construction of complex paths for the passage of water and the occupation of spaces (porous) in the macromolecular structure. Concerning oxygen permeability, with the addition of $\mathrm{ZnO} N \mathrm{NP}$, the OP values reduced up to $41 \%$ when compared to pristine chitosan film [60].

In another study also using $\mathrm{ZnO} N P$ s to improve the barrier properties of the chitosan film, a decrease in WVP with the addition of ZnO NPs was reported [64]. According to the authors, when ZnO NPs are incorporated, structures with greater firmness are formed due to the interaction of the metal oxide NP and chitosan, generating a more complex path for the water molecules to diffuse through. In this experiment, silver nanoparticles (AgNPs) were also added to the formulation, i.e. composites of Chitosan-AgNPs and Chitosan-AgNPs-ZnNPs were evaluated. The addition of both nanoparticles to chitosan also showed satisfactory and better values than just the use of one of the compounds. Moreover, they also included citronella essential oil, and this formulation containing the four components presented the lowest value of WVP [64].

The use of carbon nanotubes (CNT) in the formulation of bio-based films was reported by Liu et al. (2019) [58]. The authors combined CNT with a polymeric blend of chitosan (in different percentages $1-9 \% w / v$ film-forming dispersion) and polylactic acid (PLA). When CNT was added to the formulation with chitosan, the resistance of the formed film was $90 \%$ greater than the pristine chitosan film, which corroborates with the WPV results. The lowest value of WVP was acquired when the amount of chitosan was $7 \%$ ( $w / v$ film-forming dispersion). This decrease in WVP was possible due to the reduction in the pore diameter of the fiber, making it difficult for water molecules to pass. In addition, because of the hydrophilicity, there was a certain absorption of the water vapor by the chitosan. However, if the amount of chitosan increases a lot, this hydrophilic characteristic can damage the water vapor barrier, and this may be one of the reasons related to the increase in WVP by adding $9 \%(w / v$ film-forming dispersion) chitosan in the formulation. In addition, the viscosity of the film can increase much more with the greater addition of chitosan, making it very porous and impairing its quality [58].

In another study that addresses chitosan films together with carbon-based coatings, no significant difference was observed in relation to the WVP. However, concerning OP, there was a decrease in this permeability when the addition of carbon-based coatings occurred, according to Fernandes et al. (2018) [62]. For this research, three different acetylene fluxes in standard cubic centimeters per minute $(4 \mathrm{sccm}, 12 \mathrm{sccm}$, and $20 \mathrm{sccm})$ were used to apply the CNT coating. The lowest OP value was acquired with the largest acetylene flux, $20 \mathrm{sccm}$, due to the presence of less porosity in the film. This is because the carbon coating reduces the affinity between the oxygen and chitosan molecules. The difference between the permeability of the film for water vapor and oxygen can be explained due to the high solubility of chitosan in water, which promotes diffusion with the micro-cracks that may exist in the film, and because the $\mathrm{O}_{2}$ molecules do not degrade chitosan, this allows it to have greater coverage of the surface by the carbon coatings, having a greater barrier to oxygen [62].

\subsection{Mechanical Properties}

\subsubsection{Nanoclays}

The application of layered clay minerals with large specific surface area, such as montmorillonite (MMT), as nano reinforcement in biopolymeric matrices, has been extensively explored, giving rise to numerous studies that demonstrate its ease to blend and consequent mechanical behavior improvement [66-69].

The manner that polymer and nanoclay are held together directly rules the nanocomposite physical and mechanical properties. To be considered effective it is recommendable to achieve a nanocomposite where the two components (chitosan and MMT) are perfectly intercalated or exfoliated, therefore avoiding a tactoid blend. When the polymeric chains 
accurately diffuse through the nanoclay layers, disrupting the van der Waals forces that hold the MMT stacks together and consequently increasing the interlayer spacing and forming a well-ordered multilayer structure, an interleaved composite can be accomplished. The polar interactions between the negatively charged silicate layers and the chitosan polycationic essence in acidic media predict a favorable interconnection through the cationic exchange process [70]. More specifically, the surface negative charge instability generated by isomorphous substitution that occurred in the octahedral sheets is counterbalanced by some commutable cations (majorly $\mathrm{Na}^{+}$and $\mathrm{Ca}^{2+}$ ). In the presence of those cations adsorbed on the silicate layer, the cations inside the gallery can be readily exchanged by other cations [71,72]. Another type of nanocomposite, known as an exfoliated blend, is achieved if the clay sheets are completely separated and homogeneously dispersed in the matrix, increasing the polymer/clay interactions. If none of these composites types takes place, it leads to a non-desirable tactoid mix, where the MMT layers did not separate. In this case, complete particles will be dispersed within the polymeric matrix, diminishing the composite mechanical potential [71].

The assessment of specific mechanical parameters is essential to determine the viability of the polymer-based composite materials. By mixing the polymer matrix with the nanoparticles is projected the achievement of a nanocomposite with refined mechanical properties, structure, and integrity. The parameters that better express that evaluation are the maximum tensile strength at break (TS), the elongation at break (\%EAB), and the elastic or Young's modulus (EM). TS specifies the film strength, \%EAB indicates the material's deformation capacity, and EM measures the film rigidity [16]. Regarding chitosan films reinforced with MMT, it is properly settled by the literature that the nanoclay amount should not exceed $5 \%(w / w \mathrm{Ch})$, as expressed in Table 5 . Up to this concentration is possible to observe an increment in terms of composite strength and rigidity, and in the counterpart, a decrease in the flexibility is perceived, a consequence of limited mobility of the polymer chains in the presence of clay. With the nanofiller load overcoming the $5 \%$, the obtained materials become brittle, noting a significant decline in mechanical properties [73]. The constatation of the drop in TS for higher concentrations of MMT may be caused by some aggregation of nanoparticles with high surface energy [66].

Table 5. Mechanical properties of chitosan films reinforced with nanoclays compared to pristine chitosan films.

\begin{tabular}{|c|c|c|c|c|c|}
\hline Formulation & $\begin{array}{l}\text { Incorporation } \\
\text { Method }\end{array}$ & Tensile Strength (Relatively to Control) & Elongation at Break (Relatively to Control) & Elastic Modulus (Relatively to Control) & Ref \\
\hline $\begin{array}{c}1.5 \%(w / v) \text { Ch } \\
\text { (deacetylation degree of } \\
75-85 \%) ; \text { Glycerol } 40 \% \\
(w / w) \text { of chitosan }\end{array}$ & $\begin{array}{l}\text { Mechanical } \\
\text { stirring and } \\
\text { ultrasonic } \\
\text { homogenizer }\end{array}$ & $\begin{array}{l}\text { 1\% MMTNa: Increased } \sim 20-30 \% \\
3 \% \text { MMTNa: Increased } \sim 50 \% \\
5 \% \text { MMTNa: Increased } \sim 50 \% \\
7 \% \text { MMTNa:Increased } \sim 20-30 \% \\
9 \% \text { MMTNa: Increased } \sim 20-30 \% \\
11 \% \text { MMTNa: Increased } \sim 20-30 \%\end{array}$ & $\begin{array}{l}1 \% \text { MMTNa: Decreased } \sim 5 \% \\
3 \% \text { MMTNa: Decreased } \sim 15 \% \\
5 \% \text { MMTNa: Decreased } \sim 20 \% \\
7 \% \text { MMTNa:Decreased } \sim 10-15 \% \\
9 \% \text { MMTNa: Decreased } \sim 10-15 \% \\
11 \% \text { MMTNa: Decreased } \sim 10-15 \%\end{array}$ & Not performed & [71] \\
\hline $\begin{array}{c}2 \%(w / v) \mathrm{Ch} \\
\text { (deacetylation degree of } \\
88.8 \%) ; \text { Glycerol } 40 \% \\
(w / w) \text { of chitosan }\end{array}$ & $\begin{array}{l}\text { Mechanical } \\
\text { stirring and } \\
\text { rotor-stator } \\
\text { homogenizer } \\
\text { (Ultra-Turrax) }\end{array}$ & $\begin{array}{c}\text { 1\% MMTNa: Increased } \sim 5 \% \\
3 \% \text { MMTNa: Increased } \sim 20 \% \\
5 \% \text { MMTNa: Increased } \sim 15 \% \\
\text { 1\% MMTNa + 0.5\% REO: Increased } \sim 18 \% \\
3 \% \text { MMTNa + } 0.5 \% \text { REO: Increased } \sim 21 \% \\
5 \% \text { MMTNa + 0.5\% REO: Increased } \sim 37 \%\end{array}$ & $\begin{array}{c}\text { 1\% MMT: Decreased 5\% } \\
3 \% \text { MMT: Decreased } 19 \% \\
5 \% \text { MMT: Decreased } \sim 14 \% \\
\text { 1\% MMTNa + 0.5\%REO: Increased } \sim 18 \% \\
3 \% \text { MMTNa + 0.5\% REO: Increased } \sim 21 \% \\
5 \% \text { MMTNa + 0.5\% REO: Increased } ~ 37 \%\end{array}$ & Not performed & [72] \\
\hline $\begin{array}{l}1 \% \text { and } 2 \%(w / v) C h \\
\text { (deacetylation degree of } \\
75-85 \%) ; \text { Glycerol } 30 \% \\
(w / w) \text { of chitosan }\end{array}$ & $\begin{array}{l}\text { Reflux-solution } \\
\text { method }\end{array}$ & $\begin{array}{l}1 \% \mathrm{Ch}+3 \% \text { MMTNa: Increased } ~ 3 \% \\
1 \% \mathrm{Ch}+5 \% \text { MMTNa: Increased } \sim 17 \% \\
1 \% \mathrm{Ch}+10 \% \text { MMTNa: Increased } \sim 19 \% \\
2 \% \mathrm{Ch}+3 \% \text { MMTNa:Increased } \sim 69 \% \\
2 \% \mathrm{Ch}+5 \% \text { MMTNa: Increased } \sim 22 \% \\
2 \% \mathrm{Ch}+10 \% \text { MMTNa: Decreased } \sim 1 \%\end{array}$ & $\begin{array}{l}1 \% \mathrm{Ch}+3 \% \text { MMTNa: Decreased } \sim 64 \% \\
1 \% \mathrm{Ch}+5 \% \text { MMTNa: Decreased } \sim 38 \% \\
1 \% \mathrm{Ch}+10 \% \text { MMTNa: Decreased } \sim 60 \% \\
2 \% \mathrm{Ch}+3 \% \text { MMTNa: Decreased } \sim 61 \% \\
2 \% \mathrm{Ch}+5 \% \text { MMTNa: Decreased } \sim 68 \% \\
2 \% \mathrm{Ch}+10 \% \text { MMTNa: Decreased } \sim 75 \%\end{array}$ & $\begin{array}{l}1 \% \mathrm{Ch}+3 \% \text { MMTNa: Increased } ~ 21 \% \\
1 \% \mathrm{Ch}+5 \% \text { MMTNa: Increased } ~ 35 \% \\
1 \% \mathrm{Ch}+10 \% \text { MMTNa: Increased } \sim 27 \% \\
2 \% \mathrm{Ch}+3 \% \text { MMTNa:Increased } \sim 100 \% \\
2 \% \mathrm{Ch}+5 \% \text { MMTNa: Increased } \sim 43 \% \\
2 \% \mathrm{Ch}+10 \% \text { MMTNa: Increased } \sim 80 \%\end{array}$ & [74] \\
\hline $\begin{array}{l}1 \%(w / v) \mathrm{Ch} \\
\text { (deacetylation degree } \\
\text { greater than } 85 \%) ; \\
\text { Glycerol } 30 \%(w / w) \text { of } \\
\text { chitosan }\end{array}$ & $\begin{array}{l}\text { Mechanical } \\
\text { stirring and } \\
\text { ultrasonic } \\
\text { homogenizer }\end{array}$ & 0.5\% MMTNa: Decreased 75\% & $0.5 \%$ MMTNa: Increased 20\% & $\begin{array}{c}0.5 \% \text { MMTNa: Decreased } \sim 98 \% \\
1 \% \text { MMTNa: Decreased } \sim 97 \%\end{array}$ & [42] \\
\hline $\begin{array}{l}1.5 \%(w / v) \mathrm{Ch} \\
\text { (deacetylation degree of } \\
75 \%) ; \text { Glycerol } 30 \% \\
(w / w) \text { of chitosan }\end{array}$ & $\begin{array}{c}\text { Rotor-stator } \\
\text { homogenizer } \\
\text { (Ultra-Turrax) } \\
\text { and ultrasonic } \\
\text { bath }\end{array}$ & $\begin{array}{l}2.5 \% \text { MMTNa: Increased } \sim 82 \% \\
2.5 \% \text { MMTCa: Increased } \sim 70 \% \\
2.5 \% \text { MMT20: Increased } \sim 70 \%\end{array}$ & $\begin{array}{l}2.5 \% \text { MMTNa: Decreased } \sim 52 \% \\
2.5 \% \text { MMTCa: Decreased } \sim 65 \% \\
2.5 \% \text { MMT20: Decreased } \sim 23 \%\end{array}$ & $\begin{array}{l}2.5 \% \text { MMTNa: Increased } \sim 137 \% \\
2.5 \% \text { MMTCa: Increased } \sim 184 \% \\
2.5 \% \text { MMT20: Increased } \sim 110 \%\end{array}$ & [75] \\
\hline $\begin{array}{c}1.5 \%(w / v) \mathrm{Ch} \\
\text { (deacetylation degree of } \\
75 \%) ; \text { Glycerol } 30 \%\end{array}$ & $\begin{array}{l}\text { Rotor-stator } \\
\text { homogenizer } \\
\text { (Ultra-Turrax) }\end{array}$ & $\begin{array}{c}2.5 \% \text { MMTNa }+0.5 \% \text { GEO: Decreased } \sim 10 \% \\
2.5 \% \text { MMTNa }+1 \% \text { GEO: Decreased } \sim 26 \% \\
2.5 \% \text { MMTNa }+2 \% \text { GEO: Decreased } \sim 35 \%\end{array}$ & $\begin{array}{c}2.5 \% \text { MMTNa + 0,5\% GEO: Increased } \sim 25 \% \\
2.5 \% \text { MMTNa + } 1 \% \text { GEO: Increased } \sim 85 \% \\
2.5 \% \text { MMTNa + } 2 \% \text { GEO: Increased } \sim 100 \%\end{array}$ & $\begin{array}{l}2.5 \% \text { MMTNa+0.5\%GEO: Decreased } \sim 37 \% \\
2.5 \% \text { MMTNa + } 1 \% \text { GEO: Decreased } \sim 57 \% \\
2.5 \% \text { MMTNa + } 2 \% \text { GEO: Decreased } \sim 77 \%\end{array}$ & [25] \\
\hline $\begin{array}{c}(w / w) \text { of chitosan } \\
2 \%(w / v) \text { Ch } \\
\text { (deacetylation degree of } \\
75-85 \%)\end{array}$ & $\begin{array}{l}\text { and ultrasonic } \\
\text { homogenizer } \\
\text { Reflux-solution } \\
\text { method }\end{array}$ & $\begin{array}{c}5 \% \text { MMTNa: Increased } \sim 16 \% \\
5 \% \text { OrgMMT: Increased } \sim 14 \% \\
5 \% \text { MMTNa + TO: Increased } \sim 9 \% \\
5 \% \text { OrgMMT + TO: Increased } \sim 11 \%\end{array}$ & $\begin{array}{c}\text { 5\% MMTNa: Decreased } \sim 48 \% \\
5 \% \text { OrgMMT: Decreased } \sim 15 \% \\
5 \% \text { MMTNa + TO: Decreased } \sim 19 \% \\
5 \% \text { OrgMMT + TO: Decreased } \sim 54 \%\end{array}$ & $\begin{array}{c}5 \% \text { MMTNa: Increased } \sim 20 \% \\
5 \% \text { OrgMMT: Increased } \sim 18 \% \\
5 \% \text { MMTNa+TO: Increased } \sim 2 \% \\
5 \% \text { OrgMMT+TO: Increased } \sim 6 \%\end{array}$ & [76] \\
\hline
\end{tabular}

$\mathrm{Ch}$-chitosan; MMTNa—sodium montmorillonite; REO—rosemary essential oil; MMTCa—calcium montmorillonite; GEO—ginger essential oil; OrgMMT—organophilic montmorillonite; TO—thyme oil. 
The effectiveness of MMT's performance as a mechanical reinforcement in a chitosan biofilm does not depend only on the amount added or on the affinity between them. In 2009 , Hong et al. [71] stated that higher values of tensile strength were reached for $3 \%$ and $5 \%(w / w \mathrm{Ch}) \mathrm{MMTNa}^{+}$contents, and in contrast, lower values for elongation at break as expected. At lower concentrations, the nanoclay dispersed more uniformly through the chitosan matrix, increasing the surface attraction between the two components. In addition to the effect of the nanoclay concentration on mechanical properties, the same study also tried to understand the effect of the mixture shear rate. The authors observed that the tensile strength of the films increased until a shear rate of 16,000 rpm and it did not change significantly for superior values [71]. Later in 2011, Potarniche et al. [77] tested different $\mathrm{pH}$ values and temperatures to study the effect of these two parameters on the MMT dispersion. It was verified that the silicate layers are better intercalated when blended with chitosan at higher temperatures and $\mathrm{pH} 5$. It was supposed that with these conditions the chitosan chains are oriented preferentially between the silicate layers. Giannakas et al. (2014) [74] compared the mechanical properties of films reinforced with MMTNa + with two different chitosan dilutions in acetic acid $(1 \%$ and $2 \%(w / v))$, and the compatibility with glycerol, used as a plasticizer. Through this study, it was possible to obtain pivotal conclusions about the interaction between the different parts that formulate the nanocomposite. When diluted from $2 \%$ to $1 \%(w / v)$, the film stiffness and strength were reduced, and an increase in the elongation at break was observed. The results could be explained by higher crystallinity and less charged amine groups present in more diluted solutions. Additionally, it was constated that the addition of glycerol helps in the opening of the nanoclay structures, and with that, the composites will become more plastic, with reduced stiffness and strength and higher elongations. Souza et al. (2018) [75] incorporated different commercial MMT's in chitosan films at the level of $2.5 \%(w / w \mathrm{Ch})$. All nanoclays improved the mechanical properties with the two natural ones, $\mathrm{MMTNa}^{+}$and $\mathrm{MMTCa}^{++}$, showing the most promising results [75].

To employ this modern range of materials as an active part of the packaging for the food industry, the introduction of essential oils has been tested to increase the film's antimicrobial and antioxidant capacity [11]. These novel active compounds present in nanocomposites will in turn interact with the polymer and MMT. Abdollahi et al. (2012) [72] bound rosemary essential oil (REO) at three different levels with chitosan/MMT composites and the interaction between them was investigated. When compared with the same films without REO, it was retained that the interaction between them improved both strength and elongation at break, especially for REO at $0.5 \%$ ( $v / v$ film-forming dispersion). In contrast, Souza et al. (2019) [25] reported that chitosan/MMT films with ginger essential oil (GEO) were less resistant and rigid, and more plastic. The authors justified this with the formation of heterogeneous and discontinuous structures promoted by the incorporation of lipids into the biopolymeric matrix. Therefore, the strong polar chemical bonds chitosan-chitosan will be replaced by weaker interactions between chitosan-GEO. Giannakas et al. (2020) [76] observed similar results when introduced thyme oil in two different chitosan/MMT structures. As expected, they noted that the introduction of nanoclays, $\mathrm{MMTNa}^{+}$and OrgMMT, improved mechanical behavior. However, these good results were lowered when the thyme oil (TO) was added, acting as plasticizer when they are directly added to the chitosan matrix. Instead of adding directly the TO into the film, the authors tried another method where the essential oil was firstly adsorbed into the $\mathrm{MMTNa}^{+}$or OrgMMT, resulting in new $\mathrm{Ch}$ solution hybrids that exhibited higher performances. In this study, the authors suggested that the methodology used to incorporate the essential oil in the composite is fundamental for the interaction with chitosan/MMT, ruling the film's physical properties [76]. Ghelejlu et al. (2016) [39] perceived similar results when characterized chitosan $/ \mathrm{MMTNa}^{+}$bionanocomposites loaded with milk thistle extract. Moreover, it should be noted that they only observed a significant decrease in mechanical properties for extract concentrations superior to 1\% [39]. 
Crosslinking is another essential method to improve polymer mechanical properties. To date, few articles have explored the synergistic effect resulting from the affinity between MMT and the crosslinker, because it is difficult to understand the influence of the two components together on the mechanical properties of the films. Despite not having performed mechanical tests, Gierszewska et al. (2019) aimed to examine the influence of MMT and glutaraldehyde (GA) as crosslinker into the chitosan matrix [78]. The results suggested that the introduction of GA had a positive effect on MMT dispersion and, with that, a nanocomposite with superior physicochemical properties was obtained. However, it is impossible to determine with certainty in which way this affects mechanical behavior. Liang et al. (2019) [79] developed a chitosan nacre-like nanocomposite reinforced with $\mathrm{MMTNa}^{+}$and genipin (GP), a naturally occurring crosslinking agent. The films that contain GP exhibited higher values of strength and stiffness compared with the films that only contain $\mathrm{MMTNa}^{+}$, with the tensile strength remarkably increasing by $60 \%$ and $255 \%$ when compared to pristine chitosan. This could be mostly attributed to the crosslinked networks formed by the Schiff reaction between GP with chitosan and not to a direct interaction between GP and the nanoclay, even because the crosslinking effect reduce the free movement of the polymer molecular chain, thus diminishing the degree of hydrogen bonding between CS and the MMT sheets [79].

It can be concluded that the addition of MMT nanoparticles has a beneficial effect on the mechanical properties of chitosan films. This improvement is mostly seen for concentrations between 3\% and 5\% (w/w Ch). However, other external factors such as the addition of plasticizers, crosslinkers, extracts, and essential oils can modify, increasing, or decreasing the nanoclay performance.

\subsubsection{Cellulosic Nanofibers and Nanocrystals}

Cellulose in the form of nanofibers (CNF), nanocrystals (CNC), bacterial nanocellulose (BNC), or simply nanocellulose (NC) is the most available natural biopolymer on the planet Earth, but only lately has earned the reputation as a biodegradable nanoscaled material. These natural nanoparticles are equipped with unique optical, rheological, chemical (abundant hydroxyl groups) and, mechanical properties (high strength and high specific surface area) at low concentration, emphasizing them as a suitable agent for strengthening chitosan films [80]. Moreover, when compared to the established nanofillers, such as nanoclays, aluminum oxide particles, silica, mica, and carbon nanotubes, NC exhibits fewer public health risks [81]. The effects resulting from the incorporation of nanocellulose in composites are found in a considerable number of quality studies. The majority of them take into account NC directly hydrolyzed from pure sources, such as chemically treated microcrystalline cellulose or cotton $[50,54,82,83]$; yet, a recent interest is being demonstrated about the NC properties produced from lignocellulosic residues [84-87].

From the studies analyzed in this review, a consensus among researchers is evident that $5 \%$ of nanocellulose is enough to be considered the most suitable percentage to mechanically reinforce Ch films. Still, in 2010, Azeredo et al. [55], when evaluating the synergy between $\mathrm{CNF}$ and glycerol added to chitosan films to improve its mechanical and barrier properties, verified that the optimum conditions were the addition of precisely $15 \% \mathrm{CNF}$ and $18 \%$ glycerol. Later, Gopi et al. (2019) [88] studied the incorporation of cellulose nanofibers extracted from turmeric residue into $\mathrm{Ch}$ films at four distinct levels $(1-7 \%(w / w \mathrm{Ch}))$. The tensile strength and Young's modulus registered an increase for all concentrations, reaching the highest rise of $31 \%$ and $18 \%$, respectively, for a $5 \%$ CNF amount. The interlinkage of CNF by hydrogen bonding with Ch generated an ably reinforcing fibrillar network, which upgraded the mechanical properties considerably. In the same year, Jacob et al. [89] and Kumar et al. [90] used similar CNF levels as reinforcement, but in this specific matter, the cellulosic nanofibers were extracted from ginger rhizomes and jute fiber, respectively. The results adopted the trend of Gopi's research, but with more significant improvement percentages. Of note, the superior strength and stiffness values obtained by Jacob et al. (2019) [89], around $126 \%$ and $89 \%$, reached for the 5\% CNF. In this particular, CNF level, 
it was stated predominant and most intense intermolecular hydrogen bonds between the bionanocomposite components, data supported by the FTIR results exposed in the same study. Kumar et al. (2019) [90] also complemented, expressing the minor size and uniform distribution of CNF in the chitosan matrix could mean a minimization of pours and failure spreading points. Furthermore, for both studies, the \%EAB diminished with the nanocellulose incorporation, as expected.

When compared to the $\mathrm{Ch} / \mathrm{CNF}$, the $\mathrm{Ch} / \mathrm{CNC}$ bionanocomposites seem to indicate similar mechanical behavior. Khan et al. (2012) [91] prepared through solution casting chitosan-based biodegradable films reinforced with four different concentrations of nanocrystalline cellulose $(1-10 \%(w / w \mathrm{Ch}))$. The most noticeable mechanical improvement was attributed to films with $5 \% \mathrm{CNC}$, in which the tensile strength improved $25 \%$ and the tensile modulus $87 \%$ in comparison to pristine chitosan. The explanation behind the favorable chitosan-nanocellulose interactions could reside in the good interface between the anionic sulfate groups of $\mathrm{CNC}$ and the cationic amine groups of $\mathrm{Ch}$. Beyond this $\mathrm{CNC}$ amount, a potential aggregation of nanoparticles occurred that did not help to improve the mechanical properties. In opposed tendency, was verified a slight decrease relatively to elongation at break. This decrease suggested a tight interaction between filler and matrix, which narrowed the matrix mobility, decreasing the \%EAB [91]. To value agricultural waste, $\mathrm{Xu}$ et al. (2018) [86] isolated cellulose nanocrystals from rice straws and used them to develop high-value bionanocomposites. Following the previous research route, the authors observed a constant increment in the tensile strength until it reaches the optimal $\mathrm{CNC}$ value of $5 \%$. In addition to the potential occurrence of nanoparticle aggregation that could explain the weak interfacial $\mathrm{Ch} / \mathrm{CNC}$ compatibility after reaching the optimal amount of reinforcement, this study also attributes to the charge neutralization with poor dispersion between $-\mathrm{COO}^{-}$and $-\mathrm{NH}_{3}{ }^{+}$moieties. On the other hand, the \%EAB proportionally decreased with the rise of the CNC content [86]. Other studies, shown in Table 6, aid to conclude that the ideal $\mathrm{CNC}$ incorporation level to grasp the upper-interfacial compatibility should be around $5 \%$, curiously the same amount perceived for MMT. This percentage allows achieving optimal nanocellulose dispersion, robust hydrogen bonding, and feasible electrostatic interactions between $\mathrm{Ch}$ and CNC. Interestingly, the work of Mujtaba et al. (2017) [84] has slightly deviated from the formerly exposed tendency. This research was focused on the CNC extraction from flax fibers, which were later used in higher percentages $(5-30 \%(w / w C h))$ to reinforce $\mathrm{Ch}$ films. The authors determined that TS and EM values increased with the addition of CNC, for composites with $20 \%$ CNC revealing the optimal results. It was also noted that the introduction of nanoparticles increased the film crystallinity, which can help to explain the results.

Predominantly, chitosan matrixes reinforced with NC noted a growth in the tensile modulus and strength and a reverse decrease in the film elasticity. The nanofiller good dispersion in the chitosan matrix allied with the NC higher crystallinity, which confers strength and stiffness is essential to justify this reinforcement ability [51]. Moreover, in proper conditions, the reinforcement effect can be also explained by the connection of a welldispersed NC within the polymeric array through hydrogen bonds. At low concentrations, NC demonstrates a considerable potential to develop the percolating stiff networks, due to the high availability of free hydroxyl groups $[54,91]$. The feasibility to constitute this mechanical improved network is directly connected with three fundamental features, the nanofiller dispersion, the NC aspect ratio, and the interaction strength between the nanofiller and matrix [92]. The study by Bras et al. (2011) [93] proved that NC with a higher aspect ratio improves the film tensile strength, resulting in a percolation threshold decrease. This allows the reduction of the necessary filler content to achieve an effective reinforcing effect [93]. A higher aspect ratio contributes to nanoparticles with a higher specific surface area, which could foment an enriched connection between the chitosan and $\mathrm{NC}$, enabling a higher yield of stress transfer and restricting more efficiently the polymer chain's motion and flow [81]. It should also be kept in mind that the source and the processes involved in the cellulose isolation and subsequent extraction of the nanocellulose 
affect its intrinsic characteristics, such as crystallinity, which consequently will equally influence its mechanical reinforcement capacity [51]. Additionally, the combination of other different factors present during the bionanocomposite elaboration can partly explain the differences found in the literature for the most appropriate compositions and condition range exposed from the $\mathrm{Ch} / \mathrm{NC}$ bionanocomposites [53].

Table 6. Mechanical properties of chitosan films reinforced with nanocellulose compared to pristine chitosan films.

\begin{tabular}{|c|c|c|c|c|c|}
\hline Formulation & $\begin{array}{l}\text { Incorporation } \\
\text { Method }\end{array}$ & $\begin{array}{l}\text { Tensile Strength (Relatively to } \\
\text { Control) }\end{array}$ & $\begin{array}{l}\text { Elongation at Break } \\
\text { (Relatively to Control) }\end{array}$ & $\begin{array}{l}\text { Elastic Modulus (Relatively to } \\
\text { Control) }\end{array}$ & Ref \\
\hline $\begin{array}{l}1 \%(w / v) \mathrm{Ch} \\
\text { (deacetylation } \\
\text { degree of } 88 \% \text { ) }\end{array}$ & $\begin{array}{l}\text { Rotor-stator } \\
\text { homogenizer } \\
\text { (Ultra-Turrax) }\end{array}$ & $\begin{array}{l}1 \% \text { CNC: } \text { Increased } \sim 9 \% \\
3 \% \text { CNC: Increased } \sim 17 \% \\
5 \% \text { CNC: Increased } \sim 25 \% \\
10 \% \text { CNC: Increased } \sim 24 \%\end{array}$ & $\begin{array}{l}\text { 1\% CNC: } \text { Decreased } \sim 25 \% \\
3 \% \text { CNC: Decreased } \sim 40 \% \\
5 \% \text { CNC: } \text { Decreased } \sim 55 \% \\
10 \% \text { CNC: Decreased } \sim 55 \%\end{array}$ & $\begin{array}{l}1 \% \text { CNC: } \text { Increased } \sim 43 \% \\
3 \% \text { CNC: Increased } \sim 60 \% \\
5 \% \text { CNC: Increased } \sim 87 \% \\
10 \% \text { CNC: Increased } \sim 80 \%\end{array}$ & [91] \\
\hline $\begin{array}{c}2 \%(w / v) \mathrm{Ch} \\
\text { (deacetylation } \\
\text { degree not specified) }\end{array}$ & $\begin{array}{l}\text { Mechanical } \\
\text { stirring and } \\
\text { ultrasonic } \\
\text { homogenizer }\end{array}$ & $\begin{array}{l}\mathrm{Ch}+1 \% \mathrm{CNC}: \text { Increased } \sim 1 \% \\
\mathrm{Ch}+3 \% \mathrm{CNC}: \text { Decreased } \sim 3 \% \\
\mathrm{Ch}+5 \% \mathrm{CNC}: \text { Increased } \sim 18 \% \\
\mathrm{Ch}+10 \% \mathrm{CNC}: \text { Increased } \sim 8 \%\end{array}$ & $\begin{array}{c}\text { Ch }+1 \% \text { CNC: } \text { Decreased } \sim \\
33 \% \\
\text { Ch }+3 \% \text { CNC: }: \text { Decreased } \sim \\
14 \% \\
\text { Ch }+5 \% \text { CNC: Increased 24\% } \\
\text { Ch }+10 \% \text { CNC: Increased } \sim \\
28 \%\end{array}$ & $\begin{array}{l}\mathrm{Ch}+1 \% \mathrm{CNC}: \text { Increased } \sim 13 \% \\
\mathrm{Ch}+3 \% \mathrm{CNC}: \text { Increased } \sim 47 \% \\
\mathrm{Ch}+5 \% \mathrm{CNC}: \text { Increased } \sim 32 \% \\
\mathrm{Ch}+10 \% \mathrm{CNC}: \text { Increased } \sim 2 \%\end{array}$ & [53] \\
\hline $\begin{array}{l}1 \%(w / v) \mathrm{Ch} \\
\text { (deacetylation } \\
\text { degree of } 98 \% \text { ) }\end{array}$ & $\begin{array}{l}\text { Mechanical } \\
\text { stirring and Silent } \\
\text { Crusher-Heidolph } \\
\text { homogenizer }\end{array}$ & $\begin{array}{c}\mathrm{Ch}+5 \% \text { CNC: Increased } \sim 9 \% \\
\mathrm{Ch}+10 \% \text { CNC: Increased } \sim \\
11 \% \\
\mathrm{Ch}+20 \% \text { CNC: Increased } \sim \\
24 \% \\
\text { Ch }+30 \% \text { CNC: Increased } \sim \\
17 \%\end{array}$ & $\begin{array}{l}5 \% \text { CNC: } \text { Increased } \sim 22 \% \\
10 \% \text { CNC: Decreased } \sim 2 \% \\
20 \% \text { CNC: Decreased } \sim 5 \% \\
30 \% \text { CNC: Increased } \sim 1 \%\end{array}$ & $\begin{array}{c}\mathrm{Ch}+1 \% \text { CNC: } \text { Increased } \sim 7 \% \\
\mathrm{Ch}+3 \% \text { CNC: } \text { Increased } \sim 22 \% \\
\mathrm{Ch}+5 \% \text { CNC: Increased } \sim \\
140 \% \\
\mathrm{Ch}+10 \% \text { CNC: Increased } \sim \\
86 \%\end{array}$ & [84] \\
\hline $\begin{array}{l}4 \%(w / v) \mathrm{Ch} \\
\text { (deacetylation } \\
\text { degree of } 90 \% \text { ) }\end{array}$ & $\begin{array}{l}\text { Mechanical } \\
\text { stirring and } \\
\text { ultrasonic } \\
\text { homogenizer }\end{array}$ & $\begin{array}{l}1 \% \text { CNC: } \text { Increased } \sim 5 \% \\
3 \% \text { CNC: Increased } \sim 30 \% \\
5 \% \text { CNC: } \text { Increased } \sim 71 \% \\
8 \% \text { CNC: Increased } \sim 52 \% \\
10 \% \text { CNC: Increased } \sim 46 \% \\
15 \% \text { CNC: Increased } \sim 23 \% \\
20 \% \text { CNC: } \text { Increased } \sim 13 \%\end{array}$ & $\begin{array}{l}1 \% \text { CNC: } \text { Decreased } \sim 15 \% \\
3 \% \text { CNC: Decreased } \sim 20 \% \\
5 \% \text { CNC: Decreased } \sim 20 \% \\
8 \% \text { CNC: Decreased } \sim 35 \% \\
10 \% \text { CNC: Decreased } \sim 40 \% \\
15 \% \text { CNC: Decreased } \sim 50 \% \\
20 \% \text { CNC: Decreased } \sim 65 \%\end{array}$ & Not Performed & [86] \\
\hline $\begin{array}{l}1 \%(w / v) \mathrm{Ch} \\
\text { (deacetylation } \\
\text { degree of } 90 \% \text { ) }\end{array}$ & $\begin{array}{l}\text { Mechanical } \\
\text { stirring and } \\
\text { ultrasonic } \\
\text { homogenizer }\end{array}$ & $\begin{array}{l}\text { Ch }+2 \% \text { CNC: } \text { Increased } \sim 5 \% \\
\text { Ch }+4 \% \text { CNC: Increased } \sim 39 \% \\
\text { Ch }+6 \% \text { CNC: Increased } \sim 35 \% \\
\text { Ch }+8 \% \text { CNC: Increased } \sim 32 \%\end{array}$ & $\begin{array}{c}\text { Ch }+2 \% \text { CNC: Decreased } ~ \\
23 \% \\
\text { Ch }+4 \% \text { CNC: Decreased } ~ \\
55 \% \\
\text { Ch }+6 \% \text { CNC: Decreased } ~ \\
58 \% \\
\text { Ch }+8 \% \text { CNC: Decreased } \sim \\
59 \%\end{array}$ & $\begin{array}{l}\mathrm{Ch}+2 \% \mathrm{CNC}: \text { Increased } \sim 39 \% \\
\mathrm{Ch}+4 \% \mathrm{CNC}: \text { Increased } \sim 79 \% \\
\mathrm{Ch}+6 \% \mathrm{CNC}: \text { Increased } \sim 72 \% \\
\mathrm{Ch}+8 \% \mathrm{CNC}: \text { Increased } \sim 69 \%\end{array}$ & [54] \\
\hline $\begin{array}{c}\text { Not specified \% } \\
(w / v) \text { Ch } \\
\text { (deacetylation } \\
\text { degree of } 90 \%)\end{array}$ & $\begin{array}{l}\text { Mechanical } \\
\text { stirring and } \\
\text { ultrasonic } \\
\text { homogenizer }\end{array}$ & $\begin{array}{l}\text { Ch }+1 \% \text { CNF: Increased } \sim 10 \% \\
\text { Ch }+3 \% \text { CNF: Increased } \sim 22 \% \\
\text { Ch }+5 \% \text { CNF: Increased } \sim 31 \% \\
\text { Ch }+7 \% \text { CNF: Increased } \sim 25 \%\end{array}$ & $\begin{array}{c}\text { Ch }+1 \% \text { CNF: Decreased } \sim 8 \% \\
\text { Ch }+3 \% \text { CNF: Decreased } \sim \\
18 \% \\
\text { Ch }+5 \% \text { CNF: Decreased } \sim \\
28 \% \\
\text { Ch }+7 \% \text { CNF: Decreased } \sim \\
22 \%\end{array}$ & $\begin{array}{l}\text { Ch }+1 \% \text { CNF: Increased } \sim 7 \% \\
\text { Ch }+3 \% \text { CNF: Increased } \sim 14 \% \\
\text { Ch }+5 \% \text { CNF: Increased } \sim 18 \% \\
\text { Ch }+7 \% \text { CNF: Increased } \sim 14 \%\end{array}$ & [88] \\
\hline $\begin{array}{c}1 \%(w / v) \mathrm{Ch} \\
\text { (deacetylation } \\
\text { degree of } 75-80 \%)\end{array}$ & $\begin{array}{l}\text { Mechanical } \\
\text { stirring and } \\
\text { ultrasonic } \\
\text { homogenizer }\end{array}$ & $\begin{array}{c}\text { Ch }+1 \% \text { CNF: Increased } \sim 31 \% \\
\text { Ch }+3 \% \text { CNF: Increased } \sim 87 \% \\
\text { Ch }+5 \% \text { CNF: Increased } ~ \\
126 \% \\
\text { Ch }+7 \% \text { CNF: Increased } \sim 92 \%\end{array}$ & $\begin{array}{c}\mathrm{Ch}+1 \% \text { CNF: Decreased } \sim \\
10 \% \\
\mathrm{Ch}+3 \% \text { CNF: Decreased } \sim \\
15 \% \\
\mathrm{Ch}+5 \% \text { CNF: Decreased } \sim \\
19 \% \\
\mathrm{Ch}+7 \% \text { CNF: Decreased } \sim \\
37 \%\end{array}$ & $\begin{array}{l}\text { Ch }+1 \% \text { CNF: Increased } \sim 20 \% \\
\text { Ch }+3 \% \text { CNF: Increased } \sim 43 \% \\
\text { Ch }+5 \% \text { CNF: Increased } \sim 89 \% \\
\text { Ch }+7 \% \text { CNF: Increased } \sim 51 \%\end{array}$ & [89] \\
\hline $\begin{array}{l}1 \%(w / v) \mathrm{Ch} \\
\text { (deacetylation } \\
\text { degree of } 75 \% \text { ) }\end{array}$ & $\begin{array}{l}\text { Mechanical } \\
\text { stirring and } \\
\text { ultrasonic } \\
\text { homogenizer }\end{array}$ & $\begin{array}{c}\mathrm{Ch}+2 \% \text { BCNC: Increased } \sim \\
28 \% \\
\mathrm{Ch}+4 \% \text { BCNC: Increased } \sim \\
96 \% \\
\mathrm{Ch}+6 \% \text { BCNC: Increased } \sim \\
65 \%\end{array}$ & $\begin{array}{c}\mathrm{Ch}+2 \% \text { BCNC: Decreased } \sim \\
12 \% \\
\mathrm{Ch}+4 \% \text { BCNC: Decreased } \sim \\
30 \% \\
\mathrm{Ch}+6 \% \text { BCNC: Decreased } \sim \\
26 \%\end{array}$ & $\begin{array}{c}\text { Ch }+2 \% \text { BCNC: Increased } ~ \\
95 \% \\
\text { Ch }+4 \% \text { BCNC: Increased } ~ \\
206 \% \\
\text { Ch }+6 \% \text { BCNC: Increased } ~ \\
119 \%\end{array}$ & [57] \\
\hline
\end{tabular}

Ch-chitosan; CNC—cellulose nanocrystals; CNF-cellulose nanofibers; BCNC_bacterial nanocellulose.

\subsubsection{Metal Oxides}

Metal oxides (MO) are the most literature-referred nanoreinforcement in bionanocomposite structures for application in food packaging because, in addition to the mechanical reinforcement capacity, they also provide an extra antimicrobial efficiency to the bionanocomposite.

Among these metallic inorganic nanoreinforcements, titanium dioxide $\left(\mathrm{TiO}_{2}\right)$ has captured significant attention because of its reasonable price, good stability, photocatalytic activity, UV resistance, antibacterial properties, and nontoxicity. Siripatrawan and Kaewk- 
lin (2018) [94] implemented four different concentrations of $\mathrm{TiO}_{2}(0.25 \%, 0.5 \%, 1 \%$, and $2 \%(w / w C h))$ to reinforce chitosan films, and the mechanical properties were evaluated. The tensile strength efficacy increased with the nanoparticles introduction, with the most significant value being reached for $1 \% \mathrm{TiO}_{2}$. The scanning electron microscope images showed that for higher concentrations, an aggregation seems to occur among the particles. The authors indicated that the aptness to agglomerate is presumably due to the decreasing range between the $\mathrm{TiO}_{2}$ nanoparticles through film-forming preparation, which contributes to the increasing the impact probability between them. Moreover, this study revealed that the $\mathrm{EAB} \%$ decreases for $\mathrm{Ch} / \mathrm{TiO}_{2}$ composites, but no contrast was recorded for different concentrations. Lan et al. (2021) [95] developed $\mathrm{Ch} / \mathrm{TiO}_{2}$ films complemented with red apple pomace extract for multifunctional packaging material. The TS achieved by the composite with $0.5 \%(w / w \mathrm{Ch}) \mathrm{TiO}_{2}$ improved $21 \%$, a value strikingly similar to the one in the previous study. When adding the apple extract this mechanical parameter improved, even more, having attained a $61 \%$ growth in relation to the pristine chitosan. In another work [96], a higher increase in tensile strength value, about $90 \%$, was scored with fewer nanoparticle amounts, only $0.25 \%(w / w \mathrm{Ch})$. Curiously, against the observed trend lodged in the previous two studies, a greater increment in elongation was got, stretching more than $70 \%$ compared to the original chitosan film. To avoid the aggregation of the nanoparticles and consequently improve their dispersion in the biopolymeric matrix, Mallakpour and Madani (2015) [97] modified $\mathrm{TiO}_{2}$ with N-trimellitylimido-S-valine diacid to express biomaterial moieties through available amino acid groups. After achieving positive dispersion rates into the chitosan, the authors doubled the film TS with the introduction of $15 \% \mathrm{TiO}_{2}$.

Zinc oxide $(\mathrm{ZnO})$ is another metal oxide broadly applied in the composite field due to its noticeable antimicrobial and photocatalytic properties. In parallel to other metal oxide nanoparticles, $\mathrm{ZnO}$ nanoparticles are appraised as safe for human beings and have been handled already as food additives and packaging materials [98]. In 2010, Li et al. [99] synthesized and characterized novel chitosan/ZnO composites membranes, in which the proper quantity of nanoparticles added was distributed in a broad range of values, between $1-10 \%(w / w \mathrm{Ch})$. The composite tensile strength was better for all $\mathrm{ZnO}$ amounts added comparatively with the original membrane; however, the lowest weight assigned was the one that produced the most extraordinary results. Predominantly, it was possible to understand that the mechanical properties of chitosan film only improved to $\mathrm{ZnO}$ with concentrations up to 3\%. The authors explained that when reduced amounts of $\mathrm{ZnO}$ nanoparticles are released into the matrix, intermolecular hydrogen bonds faded and new $\mathrm{Ch} / \mathrm{ZnO}$ hydrogen bonds were assembled, which created a more flexible molecular chain. Therefore, the film tensile strength and the elongation at break suffered a boost. Mujeeb Rahman et al. (2018) [100] also attributed the best reinforce percentage that should be added to chitosan films to $1 \% \mathrm{ZnO}$. With that amount, the authors reached more $225 \%$ in tensile strength than in the same film without nanoparticles. Other studies regarding $\mathrm{ZnO}$ reported the corresponding tendency verified for $\mathrm{TiO}_{2}$, and that lower amounts are more than enough to enhance the mechanical properties of the film, as can be seen by the results exposed in Table 7 .

Table 7. Mechanical properties of chitosan films reinforced with metal oxides compared to pristine chitosan films.

\begin{tabular}{|c|c|c|c|c|c|}
\hline Formulation & $\begin{array}{l}\text { Incorporation } \\
\text { Method }\end{array}$ & $\begin{array}{l}\text { Tensile Strength (Relatively to } \\
\text { Control) }\end{array}$ & $\begin{array}{c}\text { Elongation at Break (Relatively } \\
\text { to Control) }\end{array}$ & $\begin{array}{c}\text { Elastic Modulus } \\
\text { (Relatively to Control) }\end{array}$ & Ref \\
\hline $\begin{array}{c}2 \%(w / v) \mathrm{Ch} \\
\text { (deacetylation } \\
\text { degree of } 75-85 \%)\end{array}$ & $\begin{array}{l}\text { Mechanical stirring } \\
\text { and ultrasonic } \\
\text { homogenizer }\end{array}$ & $\begin{array}{c}5 \% \mathrm{TiO}_{2}: \text { Increased } \sim 40 \% \\
10 \% \mathrm{TiO}_{2}: \text { Increased } \sim 63 \% \\
15 \% \mathrm{TiO}_{2}: \text { Increased } \sim 100 \%\end{array}$ & $\begin{array}{c}5 \% \mathrm{TiO}_{2}: \text { Increased } \sim 35 \% \\
10 \% \mathrm{TiO}_{2}: \text { Decreased } \sim 6 \% \\
15 \% \mathrm{TiO}_{2}: \text { Decreased } \sim 10 \%\end{array}$ & Not Performed & [97] \\
\hline $\begin{array}{l}2.5 \%(w / v) \mathrm{Ch} \\
\text { (deacetylation } \\
\text { degree of } 90 \% \text { ) }\end{array}$ & Mechanical stirring & $0.25 \% \mathrm{TiO}_{2}:$ Increased $\sim 90 \%$ & $0.25 \% \mathrm{TiO}_{2}:$ Increased $~ 70 \%$ & Not Performed & [96] \\
\hline $\begin{array}{l}2 \%(w / v) \mathrm{Ch} \\
\text { (deacetylation } \\
\text { degree of } 85 \% \text { ) }\end{array}$ & $\begin{array}{l}\text { Controlled- } \\
\text { temperature water } \\
\text { bath shaker and } \\
\text { ultrasonic } \\
\text { homogenizer }\end{array}$ & $\begin{array}{c}0.25 \% \mathrm{TiO}_{2}: \text { Increased } \sim 10 \% \\
0.5 \% \mathrm{TiO}_{2}: \text { Increased } \sim 20 \% \\
1 \% \mathrm{TiO}_{2}: \text { Increased } \sim 50 \% \\
2 \% \mathrm{TiO}_{2}: \text { Increased } \sim 25 \%\end{array}$ & $\begin{array}{c}0.25 \% \mathrm{TiO}_{2}: \text { Decreased } \sim 5-15 \% \\
0.5 \% \mathrm{TiO}_{2}: \text { Decreased } \sim 5-15 \% \\
1 \% \mathrm{TiO}_{2}: \text { Decreased } \sim 5-15 \% \\
2 \% \mathrm{TiO}_{2}: \text { Decreased } \sim 5-15 \%\end{array}$ & Not Performed & [94] \\
\hline
\end{tabular}


Table 7. Cont.

\begin{tabular}{|c|c|c|c|c|c|}
\hline Formulation & $\begin{array}{l}\text { Incorporation } \\
\text { Method }\end{array}$ & $\begin{array}{l}\text { Tensile Strength (Relatively to } \\
\text { Control) }\end{array}$ & $\begin{array}{c}\text { Elongation at Break (Relatively } \\
\text { to Control) }\end{array}$ & $\begin{array}{c}\text { Elastic Modulus } \\
\text { (Relatively to Control) }\end{array}$ & Ref \\
\hline $\begin{array}{l}2 \%(w / v) \mathrm{Ch} \\
\text { (deacetylation } \\
\text { degree of } 90 \% \text { ) }\end{array}$ & Mechanical stirring & $\begin{array}{c}0.5 \% \mathrm{TiO}_{2}: \text { Increased } \sim 21 \% \\
0.5 \% \mathrm{TiO}_{2}+\underset{\text { BPPE: Increased } \sim}{61 \%}\end{array}$ & $\begin{array}{c}0.5 \% \mathrm{TiO}_{2}: \text { Decreased } \sim 9 \% \\
0.5 \% \mathrm{TiO}_{2}+0.5 \mathrm{BPPE} \% \text { : Increased } \\
\sim 6 \%\end{array}$ & Not Performed & [101] \\
\hline $\begin{array}{l}2.5 \%(w / v) \mathrm{Ch} \\
\text { (deacetylation } \\
\text { degree of } 85 \% \text { ) }\end{array}$ & Mechanical stirring & $\begin{array}{c}10 \% \mathrm{TiO}_{2}: \text { Increased } \sim 40 \% \\
10 \% \mathrm{TiO}_{2}+\mathrm{APE}: \text { Increased } \sim 70 \%\end{array}$ & $\begin{array}{c}10 \% \mathrm{TiO}_{2}: \text { Increased } \sim 15 \% \\
10 \% \mathrm{TiO}_{2}+5 \% \text { APE: Increased } \sim \\
22 \%\end{array}$ & Not Performed & {$[95]$} \\
\hline $\begin{array}{l}1 \%(w / v) \mathrm{Ch} \\
\text { (deacetylation } \\
\text { degree of } 85 \% \text { ) }\end{array}$ & $\begin{array}{l}\text { Mechanical stirring } \\
\text { and ultrasonic } \\
\text { homogenizer }\end{array}$ & $\begin{array}{l}1 \% \text { ZnO: Increased } \sim 83 \% \\
2 \% \text { ZnO: Increased } \sim 78 \% \\
3 \% \text { ZnO: Increased } \sim 70 \% \\
4 \% \text { ZnO: Increased } \sim 68 \% \\
5 \% \text { ZnO: Increased } \sim 54 \% \\
6 \% \text { ZnO: Increased } \sim 24 \% \\
7 \% \text { ZnO: Increased } \sim 19 \% \\
10 \% \text { ZnO: Increased } \sim 16 \%\end{array}$ & $\begin{array}{c}\text { 1\% ZnO: Increased 138\% } \\
2 \% \text { ZnO: Increased } \sim 62 \% \\
3 \% \text { ZnO: Increased } ~ 36 \% \\
4 \% \text { ZnO: Decreased } ~ 12 \% \\
5 \% \text { ZnO: Decreased } ~ 33 \% \\
6 \% \text { ZnO: Decreased } ~ 47 \% \\
7 \% \text { ZnO: Decreased } ~ 59 \% \\
10 \% \text { ZnO: Decreased } \sim 61 \%\end{array}$ & Not Performed & [99] \\
\hline $\begin{array}{c}\text { Not specified \% } \\
(w / v) C h \\
\text { (deacetylation } \\
\text { degree unknown) }\end{array}$ & $\begin{array}{l}\text { Mechanical stirring } \\
\text { and ultrasonic } \\
\text { homogenizer }\end{array}$ & $\begin{array}{c}0.1 \% \mathrm{ZnO}: \text { Increased } \sim 15 \% \\
0.3 \% \mathrm{ZnO} \text { : Increased } ~ 50 \% \\
0.5 \% \mathrm{ZnO} \text { : Increased } \sim 70 \% \\
0.5 \% \mathrm{ZnO}+\text { NEO: Increased } ~ \\
100 \%\end{array}$ & $\begin{array}{c}0.1 \% \mathrm{ZnO}: \text { Increased } \sim 30 \% \\
0.3 \% \mathrm{ZnO} \text { : Increased } \sim 75 \% \\
0.5 \% \mathrm{ZnO} \text { : Increased } \sim 90 \% \\
0.5 \% \mathrm{ZnO}+\text { NEO: Increased } ~ \\
130 \%\end{array}$ & Not Performed & [59] \\
\hline $\begin{array}{c}2 \%(w / v) \mathrm{Ch} \\
\text { (deacetylation } \\
\text { degree of }>75 \%)\end{array}$ & Mechanical stirring & $\begin{array}{l}1 \% \mathrm{ZnO}: \text { Increased } \sim 32 \% \\
2 \% \mathrm{ZnO}: \text { Increased } \sim 67 \%\end{array}$ & $\begin{array}{l}1 \% \mathrm{ZnO}: \text { Decreased } \sim 18 \% \\
2 \% \mathrm{ZnO}: \text { Decreased } \sim 57 \%\end{array}$ & $\begin{array}{c}1 \% \mathrm{ZnO}: \text { Increased } ~ \\
47 \% \\
2 \% \mathrm{ZnO}: \text { Increased } \\
81 \%\end{array}$ & [102] \\
\hline $\begin{array}{l}2 \%(w / v) \mathrm{Ch} \\
\text { (deacetylation } \\
\text { degree of } 85 \% \text { ) }\end{array}$ & $\begin{array}{l}\text { Ultrasonic } \\
\text { homogenizer }\end{array}$ & $\begin{array}{c}0.5 \% \text { ZnO: Increased 103\% } \\
1 \% \text { ZnO: Increased 225\% } \\
1.5 \% \text { ZnO: Increased 182\% } \\
2 \% \text { ZnO: Increased 122\% }\end{array}$ & $\begin{array}{c}0.5 \% \text { ZnO: Decreased 26\% } \\
1 \% \text { ZnO: Increased 7\% } \\
1.5 \% \text { ZnO: Decreased 52\% } \\
2 \% \text { ZnO: Decreased 56\% }\end{array}$ & Not Performed & [100] \\
\hline $\begin{array}{c}\text { Not specified } \% \\
(w / v) \text { Ch } \\
\text { (deacetylation } \\
\text { degree of }>75 \% \text { ) }\end{array}$ & $\begin{array}{l}\text { Reflux-solution } \\
\text { method }\end{array}$ & $\begin{array}{l}3 \% \mathrm{ZnO}: \text { Decreased } \sim 25 \% \\
5 \% \mathrm{ZnO}: \text { Decreased } \sim 20 \% \\
7 \% \mathrm{ZnO}: \text { Decreased } \sim 15 \%\end{array}$ & $\begin{array}{l}\text { 3\% ZnO: Decreased } ~ 3 \% \\
5 \% \mathrm{ZnO}: \text { Increased } \sim 35 \% \\
7 \% \mathrm{ZnO}: \text { Increased } \sim 65 \%\end{array}$ & $\begin{array}{c}\text { 3\% ZnO: Decreased } \\
42 \% \\
5 \% \text { ZnO: Decreased } \\
40 \% \\
7 \% \text { ZnO: Decreased } \\
43 \%\end{array}$ & [63] \\
\hline $\begin{array}{l}1 \%(w / v) \mathrm{Ch} \\
\text { (deacetylation } \\
\text { degree of } 75 \% \text { ) }\end{array}$ & $\begin{array}{l}\text { Mechanical stirring } \\
\text { and ultrasonic } \\
\text { homogenizer }\end{array}$ & $\begin{array}{l}5 \% \mathrm{MgO}: \text { Increased } \sim 86 \% \\
10 \% \mathrm{MgO}: \text { Increased } \sim 26 \%\end{array}$ & $\begin{array}{l}5 \% \text { MgO: Decreased } ~ 13 \% \\
\text { 10\% MgO: Decreased } \sim 25 \%\end{array}$ & $\begin{array}{c}5 \% \mathrm{MgO}: \text { Increased } \sim \\
38 \% \\
10 \% \text { MgO: Increased } ~ \\
27 \%\end{array}$ & [103] \\
\hline $\begin{array}{l}1 \%(w / v) \mathrm{CMCh} \\
\text { (deacetylation } \\
\text { degree of } 90 \%)\end{array}$ & $\begin{array}{l}\text { Mechanical stirring } \\
\text { and ultrasonic } \\
\text { homogenizer }\end{array}$ & $\begin{array}{l}\text { 0.5\% MgO: Decreases 30-35\% } \\
\text { 1\% MgO: Decreased 10-15\% }\end{array}$ & $\begin{array}{c}0.5 \% \mathrm{MgO}: \text { Increased } \sim 142 \% \\
1 \% \mathrm{MgO}: \text { Increased } \sim 171 \%\end{array}$ & $\begin{array}{c}0.5 \% \text { MgO: Increased } \\
24 \% \\
1 \% \text { MgO: Increased } \\
88 \%\end{array}$ & [104] \\
\hline
\end{tabular}

$\mathrm{Ch}$-chitosan; $\mathrm{TiO}_{2}$ —titanium dioxide; $\mathrm{BPPE}$ —black plum peel extract; $\mathrm{APE}$-red apple pomace; $\mathrm{ZnO} —$ zinc Oxide; NEO—neem oil; $\mathrm{MgO}-$ magnesium oxide.

Other types of metal oxides, such as iron oxide $\left(\mathrm{Fe}_{3} \mathrm{O}_{4}\right)$, silica oxide $\left(\mathrm{SiO}_{2}\right)$, or magnesium oxide $(\mathrm{MgO})$, have equally been used in interaction with chitosan, but more specifically in applications related to biomedical and effluent remediation, making it difficult to recognize results from its mechanical reinforcement. However, two quality studies can be found in the literature that directly applied $\mathrm{MgO}$ in a chitosan packaging system. Silva et al. (2017) [103] fabricated $\mathrm{Ch} / \mathrm{MgO}$ thin films with improved physical properties for potential packaging application. Between the two $\mathrm{MgO}$ concentrations added ( $5 \%$ and $10 \%(w / w \mathrm{Ch}))$, the tensile strength and Young's modulus were better for the lower amount, improving $86 \%$ and $38 \%$, respectively. For both composites, the elasticity declined with the nanoparticles' integration. Once again, the aggregation is the fundamental aspect to attribute better reinforcement to $5 \%$ with scanning electron microscopy (SEM) morphology showing that $10 \% \mathrm{MgO}$ presented a relatively high number of micro-voids and pores. More recently, in 2020, Wang et al. [104] produced carboxymethyl chitosan (CMCS) and nano $\mathrm{MgO}$ for food packaging. In this case, the amount of $\mathrm{MgO}$ explored was much lower $(0.5 \%$ and $1 \%(w / w C h))$ than in the previous study. Uncommonly, the authors perceived a decrease in tensile strength for both composites compared to chitosan film. In contrast, a greater increase was observed in elastic modulus and elongation at break. The authors concluded that the blend of CMCS and $\mathrm{MgO}$ might be used as a novel food packaging when ductility and elasticity are intended. Finally, Yadav et al. (2014) [105] added 0.5\% $\left(w / w \mathrm{Ch} \mathrm{Fe}_{3} \mathrm{O}_{4}\right.$ to chitosan/graphene oxide (GO) composite. In comparison with the 
Ch/GO composite, the addition of iron oxide improved by $10 \%$ and $22 \%$, in accordance with the TS and EM.

As can be stated from Table 7, lower amounts of metal oxides should be enough to provide a better strength effect to chitosan films. By overtaking the threshold amount will occur nanoparticle aggregation and consequently that effect will vanish. Moreover, it should be noted that in these studies it is rare to find Young's modulus results, being difficult to analyze the metal oxide nanoparticle effect in the composite stiffness. Regarding the elongation at break, a great disparity of results was demonstrated.

\subsubsection{Carbon Nanotubes}

Carbon nanotubes (CNTs) are another nanoscale agent that have been labeled as ideal reinforcing filler for polymer matrixes to accomplish notable mechanical performance, because of their nanometer size, high aspect ratios, and more importantly, their remarkable strength and stiffness [106]. CNTs can be based in two different configurations, one-dimensional referred to as single-wall carbon nanotubes (SWCNTs) or two or moredimensional assigned as multi-wall carbon nanotubes (MWCNTs) that understand nested single-wall carbon nanotubes, with this last type being widely used in the preparation of polymer nanocomposites [107]. Although the favorable characteristics to form functional bionanocomposites, the creation of a homogeneous $\mathrm{Ch} / \mathrm{CNT}$ structure represents technical defiance due to the CNTs' poor dispersion. The intrinsic van der Waals attractive forces cause carbon nanoparticles to be very susceptible to aggregation processes, which makes it impossible for an appropriate scattering, therefore affecting the CNT mechanical and physical properties. To surpass this obstacle, several physical and chemical methods have been proposed, such as CNT chemical functionalization, CNT dispersion in a polymer solution by an ultrasonic bath, or in situ polymerization [108]. Different examples of chitosan films reinforced with CNTs are stated in Table 8.

Table 8. Mechanical properties of chitosan films reinforced with carbon nanotubes compared to pristine chitosan films.

\begin{tabular}{|c|c|c|c|c|c|}
\hline Formulation & $\begin{array}{l}\text { Incorporation } \\
\text { Method }\end{array}$ & $\begin{array}{l}\text { Tensile Strength (Relatively to } \\
\text { Control) }\end{array}$ & $\begin{array}{c}\text { Elongation at Break (Relatively to } \\
\text { Control) }\end{array}$ & $\begin{array}{l}\text { Elastic Modulus (Relatively to } \\
\text { Control) }\end{array}$ & Ref \\
\hline $\begin{array}{c}1 \%(w / v) \mathrm{Ch} \\
\text { (deacetylation degree } \\
\text { of } 83 \% \text { ) }\end{array}$ & $\begin{array}{c}\text { Rotor-stator } \\
\text { homogenizer } \\
\text { (Ultra-Turrax) and } \\
\text { ultrasonic } \\
\text { homogenizer }\end{array}$ & $\begin{array}{c}0.2 \% \text { MWCNT: Increased } ~ 23 \% \\
0.4 \% \text { MWCNT: Increased } ~ 78 \% \\
0.8 \% \text { MWCNT: Increased } \sim 93 \% \\
2 \% \text { MWCNT: Increased } \sim 99 \%\end{array}$ & $\begin{array}{l}0.2 \% \text { MWCNT: Decreased } \sim 27 \% \\
0.4 \% \text { MWCNT: Decreased } \sim 58 \% \\
0.8 \% \text { MWCNT: Decreased } \sim 61 \% \\
2 \% \text { MWCNT: Decreased } \sim 73 \%\end{array}$ & $\begin{array}{l}0.2 \% \text { MWCNT: Increased } \sim 49 \% \\
0.4 \% \text { MWCNT: Increased } \sim 94 \% \\
0.8 \% \text { MWCNT: Increased } \sim 99 \% \\
2 \% \text { MWCNT: Increased } \sim 97 \%\end{array}$ & [106] \\
\hline $\begin{array}{c}3 \%(w / v) \mathrm{Ch} \\
\text { (deacetylation degree } \\
\text { of } 85 \% \text { ) }\end{array}$ & Mechanical stirring & $\begin{array}{l}0.1 \% \text { MWCNT: Increased 25\% } \\
0.5 \% \text { MWCNT: Increased 59\% } \\
1 \% \text { MWCNT: Increased 119\% } \\
1.5 \% \text { MWCNT: Increased 162\% }\end{array}$ & $\begin{array}{l}0.1 \% \text { MWCNT: Increased 45\% } \\
0.5 \% \text { MWCNT: Increased 95\% } \\
1 \% \text { MWCNT: Increased 150\% } \\
1.5 \% \text { MWCNT: Increased } \sim 200 \%\end{array}$ & $\begin{array}{l}0.1 \% \text { MWCNT: Increased } \sim 136 \% \\
0.5 \% \text { MWCNT: Increased } \sim 288 \% \\
1 \% \text { MWCNT: Increased } \sim 322 \% \\
1.5 \% \text { MWCNT: Increased } \sim 384 \%\end{array}$ & [109] \\
\hline $\begin{array}{l}\text { Not specified \% }(w / v) \\
\text { Ch (deacetylation } \\
\text { degree of } 75-85 \%)\end{array}$ & Coating & $\begin{array}{c}0.1 \% \text { Raw-MWCNT: Increased 2\% } \\
0.1 \% \text { PHB-MWCNT: Increased } ~ \\
42 \%\end{array}$ & $\begin{array}{c}0.1 \% \text { Raw-MWCNT: Decreased } ~ 6 \% \\
0.1 \% \text { PHB-MWCNT: Increased } ~ \\
28 \%\end{array}$ & $\begin{array}{c}0.1 \% \text { Raw-MWCNT: Increased } \\
10 \% \\
0.1 \% \text { PHB-MWCNT: Increased } \\
24 \%\end{array}$ & [110] \\
\hline $\begin{array}{c}2 \%(w / v) \mathrm{Ch} \\
\text { (deacetylation degree } \\
\text { of } 75-85 \% \text { ) }\end{array}$ & $\begin{array}{l}\text { Mechanical stirring } \\
\text { and ultrasonic } \\
\text { homogenizer }\end{array}$ & $\begin{array}{l}0.1 \% \text { MWCNT: Increased } \sim 10 \% \\
0.5 \% \text { MWCNT: Increased } \sim 20 \% \\
0.5 \% \text { MWCNT: Increased } \sim 20 \%\end{array}$ & $\begin{array}{l}0.1 \% \text { MWCNT: Decreased } ~ 15 \% \\
0.5 \% \text { MWCNT: Decreased } ~ 30 \% \\
1 \% \text { MWCNT: Decreased } \sim 33 \%\end{array}$ & $\begin{array}{c}0.1 \% \text { CNT: Increased } \sim 10 \% \\
0.5 \% \text { CNT: Increased } \sim 40 \% \\
1 \% \text { CNT: Increased } \sim 47 \%\end{array}$ & [111] \\
\hline $\begin{array}{c}\text { 1, } 1.5,2, \text { and } 2.5 \% \\
(w / v) \text { Ch } \\
\text { (deacetylation degree } \\
\text { of } 75-85 \%)\end{array}$ & $\begin{array}{l}\text { Mechanical stirring } \\
\text { and ultrasonic } \\
\text { homogenizer }\end{array}$ & 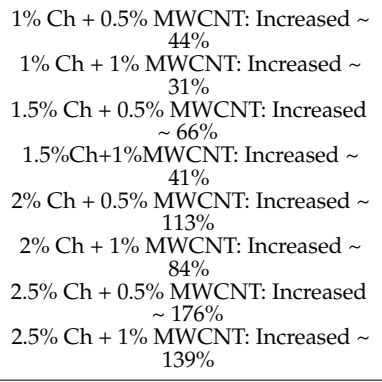 & Not Performed & $\begin{array}{c}1 \% \mathrm{Ch}+0.5 \% \text { MWCNT: Increased } ~ \\
19 \% \\
1 \% \mathrm{Ch}+1 \% \text { MWCNT: Increased } ~ \\
5 \% \\
1.5 \% \mathrm{Ch}+0.5 \% \text { MWCNT: Increased } \\
\sim 72 \% \\
1.5 \% \mathrm{Ch}+1 \% \text { MWCNT: Increased } ~ \\
55 \% \\
2 \% \mathrm{Ch}+0.5 \% \text { MWCNT: Increased } ~ \\
143 \% \\
2 \% \mathrm{Ch}+1 \% \text { MWCNT: Increased } ~ \\
70 \% \\
2.5 \% \mathrm{Ch}+0.5 \% \text { MWCNT: Increased } \\
\sim 195 \% \\
2.5 \% \mathrm{Ch}+1 \% \text { MWCNT: Increased } ~ \\
77 \% \\
\end{array}$ & [112] \\
\hline $\begin{array}{c}2 \%(w / v) \mathrm{Ch} \\
\text { (deacetylation degree } \\
\text { of } 92.5 \% \text { ) }\end{array}$ & $\begin{array}{l}\text { Mechanical stirring } \\
\text { and ultrasonic } \\
\text { homogenizer }\end{array}$ & $\begin{array}{l}1 \% \text { MWCNT: Increased } \sim 6 \% \\
2 \% \text { MWCNT: Increased } \sim 47 \% \\
5 \% \text { MWCNT: Increased } \sim 17 \% \\
10 \% \text { MWCNT: Increased } \sim 23 \%\end{array}$ & $\begin{array}{l}1 \% \text { MWCNT: Increased } \sim 57 \% \\
2 \% \text { MWCNT: Increased } \sim 70 \% \\
5 \% \text { MWCNT: Increased } \sim 34 \% \\
10 \% \text { MWCNT: Increased } \sim 53 \%\end{array}$ & Not Performed & [113] \\
\hline
\end{tabular}

Ch—chitosan; MWCNT—multi-wall carbon nanotubes; PHB—poly(3-hydroxybutyrate). 
The modification of the CNT surface by functionalization of acidic groups is an effective method of preparing a uniform dispersion of CNT in a polymer matrix. The concentrated acids are used to form carboxylic acid groups on the CNT graphitic frame surface, which owns conjugated double bonds that could be oxidized. In 2005, Wang et al. (2005) [106] proposed a novel approach to prepare fully functionalized chitosan nanocomposites reinforced with carbon nanotubes by a simple solution-evaporation method. Their plan of action passed by formulating MWCNTs with multiple surface hydroxyl groups that will favor the blend with the chitosan amino bands through hydrogen bonding, improving the interfacial strength between the two components and consequently improving their dispersion into the polymeric matrix. The functionalized MWCNTs were prepared by refluxing in a mixture of concentrated sulfuric acid and nitric acid, producing carboxylic and hydroxyl groups. The achieved results incredibly demonstrated a significant increase of the matrix mechanical properties, in which it was observed that $0.8 \%(w / w C h)$ of MWCNTs is enough to enhance the composite strength and stiffness above $90 \%$ when compared to those of neat $\mathrm{Ch}$. On behalf of the robust interactions between Ch and MWCNT, higher forces were required to surmount the molecular bonding energy, and thereafter, elastic modulus and tensile strength increased. This methodology proved to be effective in forming a strong hydrogen bond with chitosan, but despite continuing to show good reinforcement rates, the change from $0.8 \%$ to $2 \%$ MWCNTs was not justified. The morphology images identified a nanoparticle aggregation, which can justify the stabilization of tensile strength for higher MWCNTs concentrations. Ke et al. (2007) [114] used a nucleophilic substitution reaction to create covalently functionalized carbon nanotubes. The covalent linkages shaped through the reaction between the $\mathrm{Ch}$ amino groups and the acyl chloride groups of the modified CNTs will promote more stable and effective blends. Nevertheless, the employed methodology included critical and risky steps to be performed. Two years later, Liu et al. [109] proposed an alternate and steadier approach to prepare chitosan/MWCNT nanocomposites using poly(styrene sulfonic acid) functionalized MWCNTs. The sulfonic acid groups generated supplied the necessary chemical reactivity and interfacial compatibility between MWCNT and Ch. The authors observed a significantly constant growth in TS and EM values with the increase of MWCNT added. For a nanoparticle concentration of $1.5 \%(w / w C h)$, it was incredibly accomplished an increment of $162 \%$ and $384 \%$ for these parameters, revealing the vast capacity that modified MWCNTs may have to strengthen the $\mathrm{Ch}$ biofilm. In this academic study, there was an increase in the $\mathrm{EAB} \%$ with the introduction of MWCNTs in the film, reaching double the elongation values for incorporations of nanoparticles above $1 \%$. The small amount of water absorbed linked with the sulfonic acid groups added through hydrogen-bonds could contribute to the elongation growth. In addition to the nanoparticle distribution, a precise alignment of CNTs is crucial in the quality of the resultant nanocomposite, as stated by Ong et al. (2011) [110]. In their study, the chitosan matrix was reinforced with aligned poly(3-hydroxybutyrate) (PHB)-functionalized MWCNTs, in which the bulk alignment was accomplished using a simple filtration method. A chitosan composite with raw MWCNT was also produced to compare the effect of the functionalization. Comparing the two developed matrixes with pristine chitosan, it was possible to observe a significant mechanical difference between them. The raw-MWCNTs/Ch only lightly increases the TS and the EM values by $1.6 \%$ and $9.9 \%$, respectively, while on the other hand, the presence of PHB-MWCNT considerably raises the TS of the chitosan matrix by $41.8 \%$ and increases the EM by $24.1 \%$. In both membranes occurred a decrease in flexibility. Supporting the results previously exposed, these superior mechanical properties of the Ch/PHB-MWCNT nanocomposite membrane can be imputed to the suitable nanoparticle dispersion and their deep affinity with the chitosan matrix. Furthermore, the initial bulk alignment performer in the MWCNTs played an essential role in upgrading the nanocomposite mechanical properties. More recently, Wang et al. (2019) [113] developed high-performance chitosan membranes reinforced with polydopamine functionalized MWCNTs, followed by an ion crosslinking with sulfuric acid. 
The MWCNTs amounts added were superior to the other works, reaching $10 \%$; however, it was for the $2 \%$ concentration that the greatest increase in TS and $\mathrm{EAB} \%$ was observed.

As seen formerly, obtaining maximum compatibility between $\mathrm{Ch}$ and CNT is crucial in the nanocomposite preparation. Bearing that in mind, Iamsamai et al. (2010) [115] evaluated if the chitosan degree of deacetylation (\%DD) sustained some kind of effect on the noncovalent surface modification of multiwall carbon nanotubes dispersion. For that purpose, $12.5 \mathrm{mg}$ of MWCNTs were added to different solutions of chitosan comprising a set volume of $50 \mathrm{~mL}$ but distinct \%DD $(61,71,78,84,90$, or 93). Zeta potential, centrifugation, and UV-Visible spectroscopy measurements suggested that the dispersion and stability of MWCNTs could be adequately improved when using chitosan with the lowest degree of deacetylation (61\%DD) perhaps due to MWCNTs higher surface coverage. Although these data require mechanical tests to prove they are related, which was not provided by this scientific article, they can still be strong indicators. Bakhtiari et al. (2019) [112] combined four different chitosan percentages $(1 \%, 1.5 \%, 2 \%$, and $2.5 \%(w / w \mathrm{Ch}))$ as polymer matrix and two percentages $(0.5 \%$ and $1 \%(w / w C h))$ of MWCNTs as reinforcement. As reported by the authors, the results of mechanical assays showed that the combination of $2.5 \%$ $(w / v) \mathrm{Ch}+0.5 \%$ MWCNTs nanocomposite film registered the highest strength, which was increased by $176 \%$ (from 18.26 MPa to $50.46 \mathrm{MPa}$ ) and Young's modulus film increased by $195 \%$ (from $406 \mathrm{MPa}$ to $1197 \mathrm{MPa}$ ) when compared to the pristine $\mathrm{Ch}$ film. The higher concentration of $\mathrm{Ch}(2.5 \% \mathrm{w} / \mathrm{v})$ in solution engenders more entangled $\mathrm{Ch}$ molecules and more connections to MWCNTs in parallel to a lower concentration.

Ensuing this chapter's aim is also newsworthy to approach the synergy demonstrated between the carbon nanotubes and another nanofiller. Tang et al. (2009) [107] successfully prepared a chitosan ternary nanocomposite with two-dimensional $\mathrm{MMTNa}^{+}$platelets and CNTs by solution-intercalation/mixing method in acid media. With dynamic mechanical measurement, the authors concluded that the chitosan/clay/carbon nanotube composite has better storage modulus than that for the corresponding binary chitosan/clay or chitosan/CNT nanocomposites with the identical filler content $(3 \%$ ( $w / w \mathrm{Ch}))$. In two other studies, Bibi et al. [116] used a prompt and simple procedure to prepare functional chitosan nanocomposite films incorporating silver nanoparticles, gold nanoparticles, and CNTs with the support of ultrasound-assisted in situ synthesis. In both cases, a slight increase was observed in TS, toughness, and EAB\% after CNTs inclusion in the composite, showing a good inference between different nanoparticles [116,117].

After exploring carbon nanotubes' mechanical capacity, it is possible to deduce that in comparison to other analyzed nanoreinforcements, CNTs grant more tensile strength and elastic modulus with fewer particle concentrations. The good affinity these particles possess after some specific functionalization allows the composite to have high elongation rates. Furthermore, other factors such as good dispersion, alignment, and interaction with chitosan intrinsic parameters are essential to determine nanoparticle performance.

Other fillers in addition to nanoclays, cellulose nanofibers and nanocrystals, carbon nanotubes, and metal oxides are also being tested to prepare nanocomposites for food packaging applications. Yet, the information is still limited, and more research is needed in order to apprehend the significance of the current knowledge. Lignin, for example, is being considered by some authors as an option. Chitosan-based composite has been incorporated with lignin nano or macroparticles and their influence on the film's structure for application as packaging films was investigated [118-121]. After cellulose, lignin is the second most abundant non-food component of biomass and is well-known for an overly complex structure. The richness of functional groups such as phenolic, carboxylic, and aliphatic hydroxyl groups could confer to the composite an increased antioxidant and antimicrobial activity. However, it is challenging to blend lignin with other polymers due to its brittle feature and pauper dispersion [118]. Rai et al. (2017) [118] isolated lignin from sugarcane bagasse, and then various fractions were added into chitosan solutions to acquire a final concentration of $100-400 \mathrm{mg} / 100 \mathrm{~mL}(w / v)$ in chitosan solution. The authors demonstrated a considerable decrease in tensile strength and elongation at break (\%) with 
lignin incorporation, in which the lignin brittle characteristics could represent the response by the verified reduction in the film's ductile properties. Jaganathan et al. (2018) [120] successfully isolated lignin from Artocarpus heterophyllus peels. In this particular study, an increase was observed in tensile strength, but elastic modulus and elongation at break (\%) decreased with the introduction of lignin into the polymeric matrix. Regarding water vapor permeability, this study shows an increase of porosity and consequently higher values for this specific property for chitosan-lignin blends [120]. Therefore, more knowledge on the interaction of nanolignin with biopolymers, such as chitosan, can help to clarify the prospects of using this non-food component of biomass, contributing to the circular economy and bioeconomy.

\section{Conclusions and Final Remarks}

In this review, the analysis made on bionanocomposites characteristics allowed us to confirm that the incorporation of nanoparticles provides a significant reinforcement of the biopolymer's barrier and mechanical properties. The type of nanocomposite, its aspect ratio, and the amount added to the chitosan film are crucial to determine the affinity established between both, and consequently, to obtain a good particle dispersion and percolation through the matrix. In the case of montmorillonite and nanocellulose, there seems to be a better reinforcement for concentrations between $2-5 \%$, while for metal oxides and carbon nanotubes, it is observed that smaller amounts are sufficient to reach the same reinforcement values. This percentage allows achieving optimal nanofiller dispersion, while above these values, nanoparticles tend to aggregate, which will make films more brittle and more prone to gas diffusion. Another inference is that when the nanofillers are incorporated into the film, strong chemical bonds may be formed between the components; yet, in the case of carbon nanotubes, a functionalization is required to improve their effectiveness. Nonetheless, some other factors can explain discrepancies to the trends normally observed, e.g., the intrinsic chitosan features (degree of deacetylation and molecular weight), the addition of plasticizers (e.g., glycerol), natural extracts, essential oils, or crosslinkers. Furthermore, the technique employed to incorporate the nanoparticles, e.g., the application or not of ultrasounds bath homogenizer, can explain the differences registered between bionanocomposites with the same number of nanoparticles.

Present challenges toward the production and application of chitosan nanocomposites in the food packaging industry, on a large scale, are mainly related to their high costs when compared to the traditional petroleum-based plastics. But other challenges limit still its application. More knowledge is needed on the ecotoxicity and toxicity of the nanofillers being applied and on their potential migration to food. Additionally, ecofriendly, and more sustainable strategies for the production of nanofillers should be envisaged and other nanofillers could also be tested in order to identify promising options. This will provide more information on the factors that may hinder the full application of chitosan nanocomposites and other bionanocomposites in the food packaging industry and make it easier to achieve future developments in this area.

Author Contributions: The review paper was planned and written with the contributions of all the authors. Conceptualization, J.P., V.G.L.S., A.L.F., and I.C.; methodology, J.P., C.D.d.P., and V.G.L.S.; resources, J.P., C.D.d.P., and V.G.L.S.; writing-original draft preparation, J.P., C.D.d.P., and V.G.L.S.; writing-review and editing, A.L.F. and I.C.; supervision, A.L.F. and I.C.; funding acquisition, A.L.F. and I.C. All authors have read and agreed to the published version of the manuscript.

Funding: This research was funded by national funding by FCT, Foundation for Science and Technology, through the individual research grant (SFRH/BD/144346/2019) of J.P. This study was also supported by the Associate Laboratory for Green Chemistry-LAQV, which is financed by national funds from FCT/MCTES (UIDB/50006/2020 and UIDP/50006/2020) and by the Mechanical Engineering and Resource Sustainability Center-MEtRICs, which is financed by national funds from FCT/MCTES (UIDB/04077/2020 and UIDP/04077/2020).

Conflicts of Interest: The authors declare no conflict of interest. 


\section{References}

1. Souza, V.G.L.; Fernando, A.L. Nanoparticles in food packaging: Biodegradability and potential migration to food-A review. Food Packag. Shelf Life 2016, 8, 63-70. [CrossRef]

2. Fortunati, E.; Luzi, F.; Yang, W.; Kenny, J.M.; Torre, L.; Puglia, D. Bio-based nanocomposites in food packaging. In Nanomaterials for Food Packaging; Elsevier: Amsterdam, The Netherlands, 2018; pp. 71-110. ISBN 9780323512718.

3. Lambert, S.; Wagner, M.; Wagner, M. Environmental performance of bio-based and biodegradable plastics: The road ahead. Chem. Soc. Rev. 2017, 46, 6855-6871. [CrossRef] [PubMed]

4. Souza, V.G.L.; Pires, J.R.A.; Rodrigues, C.; Coelhoso, I.M.; Fernando, A.L. Chitosan Composites in Packaging Industry-Current Trends and Future Challenges. Polymers 2020, 12, 417. [CrossRef] [PubMed]

5. Andrade, M.A.; Barbosa, C.H.; Souza, V.G.L.; Coelhoso, I.M.; Reboleira, J.; Bernardino, S.; Ganhão, R.; Mendes, S.; Fernando, A.L.; Vilarinho, F.; et al. Novel Active Food Packaging Films Based on Whey Protein Incorporated with Seaweed Extract: Development, Characterization, and Application in Fresh Poultry Meat. Coatings 2021, 11, 229. [CrossRef]

6. Kowalczyk, D.; Baraniak, B. Effect of candelilla wax on functional properties of biopolymer emulsion films-A comparative study. Food Hydrocoll. 2014, 41, 195-209. [CrossRef]

7. Saratale, R.G.; Cho, S.K.; Ghodake, G.S.; Shin, H.S.; Saratale, G.D.; Park, Y.; Lee, H.S.; Bharagava, R.N.; Kim, D.S. Utilization of noxious weed water hyacinth biomass as a potential feedstock for biopolymers production: A novel approach. Polymers 2020, 12, 1704. [CrossRef] [PubMed]

8. Suwanamornlert, P.; Kerddonfag, N.; Sane, A.; Chinsirikul, W.; Zhou, W.; Chonhenchob, V. Poly(lactic acid)/poly(butylenesuccinate-co-adipate) (PLA/PBSA) blend films containing thymol as alternative to synthetic preservatives for active packaging of bread. Food Packag. Shelf Life 2020, 25, 100515. [CrossRef]

9. Rodrigues, C.; Souza, V.G.L.; Rashad, M.; Pari, L.; Outzourhit, A.; Fernando, A.L. Mucilage extraction from Opuntia spp for production of biofilms. Eur. Biomass Conf. Exhib. Proc. 2019, 1459.

10. Souza, V.G.L.; Pires, J.R.; Vieira, É.T.; Coelhoso, I.M.; Duarte, M.P.; Fernando, A.L. Shelf Life Assessment of Fresh Poultry Meat Packaged in Novel Bionanocomposite of Chitosan/Montmorillonite Incorporated with Ginger Essential Oil. Coatings 2018, 8, 177. [CrossRef]

11. Pires, J.R.A.; de Souza, V.G.L.; Fernando, A.L. Chitosan/montmorillonite bionanocomposites incorporated with rosemary and ginger essential oil as packaging for fresh poultry meat. Food Packag. Shelf Life 2018, 17, 142-149. [CrossRef]

12. Ali, A.; Ahmed, S. A review on chitosan and its nanocomposites in drug delivery. Int. J. Biol. Macromol. 2018, 109, 273-286. [CrossRef]

13. Hubbe, M.A.; Ferrer, A.; Tyagi, P.; Yin, Y.; Salas, C.; Pal, L.; Rojas, O.J. Nanocellulose in thin films, coatings, and plies for packaging applications: A review. BioResources 2017, 12, 2143-2233. [CrossRef]

14. Noshirvani, N.; Ghanbarzadeh, B.; Rezaei, R.; Hashemi, M.; Rezaei Mokarram, R.; Hashemi, M.; Rezaei, R.; Hashemi, M. Novel active packaging based on carboxymethyl cellulose-chitosan-ZnO NPs nanocomposite for increasing the shelf life of bread. Food Packag. Shelf Life 2017, 11, 106-114. [CrossRef]

15. Alves, V.L.C.D.; Rico, B.P.M.; Cruz, R.M.S.; Vicente, A.A.; Khmelinskii, I.; Vieira, M.C. Preparation and characterization of a chitosan film with grape seed extract- carvacrol microcapsules and its effect on the shelf-life of refrigerated Salmon (Salmo salar). Lwt Food Sci. Technol. 2018, 89, 525-534. [CrossRef]

16. Kumar, S.; Mukherjee, A.; Dutta, J. Chitosan based nanocomposite fi lms and coatings: Emerging antimicrobial food packaging alternatives. Trends Food Sci. Technol. 2020, 97, 196-209. [CrossRef]

17. Alves, V.D.; Costa, N.; Coelhoso, I.M. Barrier properties of biodegradable composite films based on kappa-carrageenan/pectin blends and mica flakes. Carbohydr. Polym. 2010, 79, 269-276. [CrossRef]

18. Siracusa, V. Food Packaging Permeability Behaviour: A Report. Int. J. Polym. Sci. 2012, 2012, 302029. [CrossRef]

19. Souza, V.G.L.; Fernando, A.L.; Pires, J.R.A.; Rodrigues, P.F.; Lopes, A.A.S.S.; Fernandes, F.M.B. Physical properties of chitosan films incorporated with natural antioxidants. Ind. Crop. Prod. 2017, 107, 565-572. [CrossRef]

20. Ferreira, A.R.V.; Torres, C.A.V.; Freitas, F.; Sevrin, C.; Grandfils, C.; Reis, M.A.M.; Alves, V.D.; Coelhoso, I.M. Development and characterization of bilayer films of FucoPol and chitosan. Carbohydr. Polym. 2016, 147, 8-15. [CrossRef]

21. Tunç, S.; Duman, O.; Polat, T.G. Effects of montmorillonite on properties of methyl cellulose/carvacrol based active antimicrobial nanocomposites. Carbohydr. Polym. 2016, 150, 259-268. [CrossRef]

22. Shankar, S.; Rhim, J. Bionanocomposite films for food packaging applications. Ref. Modul. Food Sci. 2018, 1-10. [CrossRef]

23. Jamróz, E.; Kopel, P.; Tkaczewska, J.; Dordevic, D.; Jancikova, S.; Kulawik, P.; Milosavljevic, V.; Dolezelikova, K.; Smerkova, K.; Svec, P.; et al. Nanocomposite Furcellaran Films-the Influence of Nanofillers on Functional Properties of Furcellaran Films and Effect on Linseed Oil Preservation. Polymers 2019, 11, 2046. [CrossRef]

24. Pires, J.R.A.; Souza, V.G.L.; Fernando, A.L. Production of Nanocellulose from Lignocellulosic Biomass Wastes: Prospects and Limitations. In Innovation, Engineering and Entrepreneurship; Machado, J., Soares, F., Veiga, G., Eds.; Lecture Notes in Electrical Engineering; Springer International Publishing: Cham, Switzerland, 2019; Volume 505, pp. 719-725. ISBN 978-3-319-91333-9.

25. Souza, V.G.L.; Pires, J.R.A.; Rodrigues, C.; Rodrigues, P.F.; Lopes, A.; Silva, R.J.; Caldeira, J.; Duarte, M.P.; Fernandes, F.B.; Coelhoso, I.M.; et al. Physical and Morphological Characterization of Chitosan/Montmorillonite Films Incorporated with Ginger Essential Oil. Coatings 2019, 9, 700. [CrossRef] 
26. Bharimalla, A.K.; Deshmukh, S.P.; Vigneshwaran, N.; Patil, P.G.; Prasad, V.; Deshmukh, S.P.; Vigneshwaran, N.; Patil, P.G.; Prasad, V. Nanocellulose-Polymer Composites for Applications in Food Packaging: Current Status, Future Prospects and Challenges Nanocellulose-Polymer Composites for Applications in Food Packaging: Current. Polym. Plast. Technol. Eng. 2017, 56, 805-823. [CrossRef]

27. Souza, V.G.L.; Pires, J.R.A.; Rodrigues, C.; Coelhoso, I.; Fernando, A.L. Novel Approaches for Chitin/Chitosan Composites in the Packaging Industry. In Chitin- and Chitosan-Based Biocomposites for Food Packaging Applications; Jacob, J., Loganathan, S., Thomas, S., Eds.; CRC Press: Boca Raton, FL, USA, 2020; pp. 87-96. ISBN 9780429299605.

28. Sionkowska, A.; Michalska-Sionkowska, M.; Walczak, M. Preparation and characterization of collagen/hyaluronic acid/chitosan film crosslinked with dialdehyde starch. Int. J. Biol. Macromol. 2020, 149, 290-295. [CrossRef] [PubMed]

29. Wang, W.; Meng, Q.; Li, Q.; Liu, J.; Zhou, M.; Jin, Z.; Zhao, K. Chitosan derivatives and their application in biomedicine. Int. J. Mol. Sci. 2020, 21, 487. [CrossRef] [PubMed]

30. Yadav, A.K.; Dhiman, T.K.; Lakshmi, G.B.V.S.; Berlina, A.N.; Solanki, P.R. A highly sensitive label-free amperometric biosensor for norfloxacin detection based on chitosan-yttria nanocomposite. Int. J. Biol. Macromol. 2020, 151, 566-575. [CrossRef]

31. Wang, Z.; Yan, F.; Pei, H.; Yan, K.; Cui, Z.; He, B.; Fang, K.; Li, J. Environmentally-friendly halloysite nanotubes@chitosan/polyvinyl alcohol/non-woven fabric hybrid membranes with a uniform hierarchical porous structure for air filtration. J. Memb. Sci. 2020, 594, 117445. [CrossRef]

32. Ali, N.; Khan, A.; Bilal, M.; Malik, S.; Badshah, S.; Iqbal, H.M.N. Chitosan-based bio-composite modified with thiocarbamate moiety for decontamination of cations from the aqueous media. Molecules 2020, 25, 226. [CrossRef]

33. Prokhorov, E.; Luna-Bárcenas, G. Negative electrical tunability of chitosan-graphene oxide nanocomposites. Appl. Phys. A Mater. Sci. Process. 2020, 126, 1-8. [CrossRef]

34. Paul, D.R.; Robeson, L.M. Polymer nanotechnology: Nanocomposites. Polymer 2008, 49, 3187-3204. [CrossRef]

35. Souza, V.G.L.; Pires, J.R.A.; Vieira, É.T.; Coelhoso, I.M.; Duarte, M.P.; Fernando, A.L. Activity of chitosan-montmorillonite bionanocomposites incorporated with rosemary essential oil: From in vitro assays to application in fresh poultry meat. Food Hydrocoll. 2019, 89, 241-252. [CrossRef]

36. da Silva Scudeler, C.G.; de Lima Costa, T.; Cortez-Vega, W.R.; Prentice, C.; Fonseca, G.G. Development and characterization of Nile tilapia (Oreochromis niloticus) protein isolate-based biopolymer films incorporated with essential oils and nanoclay. Food Packag. Shelf Life 2020, 25, 100542. [CrossRef]

37. Xu, D.; Qin, H.; Ren, D. Prolonged preservation of tangerine fruits using chitosan/montmorillonite composite coating. Postharvest Biol. Technol. 2018, 143, 50-57. [CrossRef]

38. Liu, S.; Cai, P.; Li, X.; Chen, L.; Li, L.; Li, B. Effect of film multi-scale structure on the water vapor permeability in hydroxypropyl starch (HPS)/Na-MMT nanocomposites. Carbohydr. Polym. 2016, 154, 186-193. [CrossRef]

39. Beigzadeh Ghelejlu, S.; Esmaiili, M.; Almasi, H. Characterization of chitosan-nanoclay bionanocomposite active films containing milk thistle extract. Int. J. Biol. Macromol. 2016, 86, 613-621. [CrossRef]

40. Lee, M.H.; Kim, S.Y.; Park, H.J. Effect of halloysite nanoclay on the physical, mechanical, and antioxidant properties of chitosan films incorporated with clove essential oil. Food Hydrocoll. 2018, 84, 58-67. [CrossRef]

41. Nouri, A.; Yaraki, M.T.; Ghorbanpour, M.; Agarwal, S.; Gupta, V.K. Enhanced Antibacterial effect of chitosan film using Montmorillonite/CuO nanocomposite. Int. J. Biol. Macromol. 2017, 109, 1219-1231. [CrossRef] [PubMed]

42. Llanos, J.H.R.; Tadini, C.C. Preparation and characterization of bio-nanocomposite films based on cassava starch or chitosan, reinforced with montmorillonite or bamboo nanofibers. Int. J. Biol. Macromol. 2018, 107, 371-382. [CrossRef]

43. Zou, Y.; Zhang, C.; Wang, P.; Zhang, Y.; Zhang, H. Electrospun chitosan/polycaprolactone nanofibers containing chlorogenic acid-loaded halloysite nanotube for active food packaging. Carbohydr. Polym. 2020, 247, 116711. [CrossRef] [PubMed]

44. Yousefi, P.; Hamedi, S.; Garmaroody, E.R.; Koosha, M. Antibacterial nanobiocomposite based on halloysite nanotubes and extracted xylan from bagasse pith. Int. J. Biol. Macromol. 2020, 160, 276-287. [CrossRef] [PubMed]

45. Wang, Y.; Yi, S.; Lu, R.; Sameen, D.E.; Ahmed, S.; Dai, J.; Qin, W.; Li, S.; Liu, Y. Preparation, characterization, and 3D printing verification of chitosan/halloysite nanotubes/tea polyphenol nanocomposite films. Int. J. Biol. Macromol. 2021, 166, 32-44. [CrossRef]

46. ASTM International. ASTM D3985-05, Standard Test Method for Oxygen Gas Transmission Rate through Plastic Film and Sheeting Using a Coulometric Sensor; ASTM International: West Conshohocken, PA, USA, 2017.

47. Akrami-Hasan-Kohal, M.; Ghorbani, M.; Mahmoodzadeh, F.; Nikzad, B. Development of reinforced aldehyde-modified kappacarrageenan/gelatin film by incorporation of halloysite nanotubes for biomedical applications. Int. J. Biol. Macromol. 2020, 160, 669-676. [CrossRef] [PubMed]

48. Gómez, H.C.; Serpa, A.; Velásquez-Cock, J.; Gañán, P.; Castro, C.; Vélez, L.; Zuluaga, R. Vegetable nanocellulose in food science: A review. Food Hydrocoll. 2016, 57, 178-186. [CrossRef]

49. Mondal, S. Preparation, properties and applications of nanocellulosic materials. Carbohydr. Polym. 2017, 163, 301-316. [CrossRef] [PubMed]

50. Dehnad, D.; Emam-djomeh, Z.; Mirzaei, H. Optimization of physical and mechanical properties for chitosan-Nanocellulose biocomposites. Carbohydr. Polym. 2014, 105, 222-228. [CrossRef] [PubMed]

51. Pires, J.R.A.; Souza, V.G.L.; Fernando, A.L. Valorization of energy crops as a source for nanocellulose production-Current knowledge and future prospects. Ind. Crop. Prod. 2019, 140, 111642. [CrossRef] 
52. Ferrer, A.; Pal, L.; Hubbe, M. Nanocellulose in packaging: Advances in barrier layer technologies. Ind. Crop. Prod. 2017, 95, 574-582. [CrossRef]

53. Corsello, F.A.; Bolla, P.A.; Anbinder, P.S.; Serradell, M.A.; Amalvy, J.I.; Peruzzo, P.J. Morphology and properties of neutralized chitosan-cellulose nanocrystals biocomposite films. Carbohydr. Polym. 2017, 156, 452-459. [CrossRef]

54. Yadav, M.; Behera, K.; Chang, Y.H.; Chiu, F.C. Cellulose nanocrystal reinforced chitosan based UV barrier composite films for sustainable packaging. Polymers 2020, 12, 202. [CrossRef]

55. Azeredo, H.M.C.; Mattoso, L.H.C.; Avena-Bustillos, R.J.; Filho, G.C.; Munford, M.L.; Wood, D.; McHugh, T.H. Nanocellulose reinforced chitosan composite films as affected by nanofiller loading and plasticizer content. J. Food Sci. 2010, 75, 1-7. [CrossRef]

56. Zhang, X.; Li, Y.; Guo, M.; Jin, T.Z.; Arabi, S.A.; He, Q.; Ismail, B.B.; Hu, Y.; Liu, D. Antimicrobial and UV Blocking Properties of Composite Chitosan Films with Curcumin Grafted Cellulose Nanofiber. Food Hydrocoll. 2021, 112, 106337. [CrossRef]

57. Salari, M.; Khiabani, M.S.; Mokarram, R.R.; Ghanbarzadeh, B.; Kafil, H.S. Development and evaluation of chitosan based active nanocomposite films containing bacterial cellulose nanocrystals and silver nanoparticles. Food Hydrocoll. 2018, 84, 414-423. [CrossRef]

58. Liu, Y.; Wang, S.; Lan, W.; Qin, W. Fabrication of polylactic acid/carbon nanotubes/chitosan composite fibers by electrospinning for strawberry preservation. Int. J. Biol. Macromol. 2019, 121, 1329-1336. [CrossRef] [PubMed]

59. Sanuja, S.; Agalya, A.; Umapathy, M.J. Synthesis and characterization of zinc oxide-neem oil-chitosan bionanocomposite for food packaging application. Int. J. Biol. Macromol. 2015, 74, 76-84. [CrossRef] [PubMed]

60. Yadav, S.; Mehrotra, G.K.; Dutta, P.K. Chitosan based ZnO nanoparticles loaded gallic-acid films for active food packaging. Food Chem. 2021, 334, 127605. [CrossRef] [PubMed]

61. Kalaycıŏlu, Z.; Kahya, N.; Adımcılar, V.; Kaygusuz, H.; Torlak, E.; Akın-Evingür, G.; Erim, F.B. Antibacterial nano cerium oxide/chitosan/cellulose acetate composite films as potential wound dressing. Eur. Polym. J. 2020, 133, 109777. [CrossRef]

62. Fernandes, C.; Calderon, V.S.; Ballesteros, L.F.; Cerqueira, M.A.; Pastrana, L.M.; Teixeira, J.A.; Ferreira, P.J.; Carvalho, S. Carbonbased sputtered coatings for enhanced chitosan-based films properties. Appl. Surf. Sci. 2018, 433, 689-695. [CrossRef]

63. Boura-Theodoridou, O.; Giannakas, A.; Katapodis, P.; Stamatis, H.; Ladavos, A.; Barkoula, N.-M. Performance of ZnO/chitosan nanocomposite films for antimicrobial packaging applications as a function of $\mathrm{NaOH}$ treatment and glycerol/PVOH blending. Food Packag. Shelf Life 2020, 23, 100456. [CrossRef]

64. Motelica, L.; Ficai, D.; Ficai, A.; Truşcă, R.-D.; Ilie, C.-I.; Oprea, O.-C.; Andronescu, E. Innovative Antimicrobial Chitosan/ZnO/Ag NPs/Citronella Essential Oil Nanocomposite-Potential Coating for Grapes. Foods 2020, 9, 1801. [CrossRef]

65. Sanuja, S.; Agalya, A.; Umapathy, M.J. Studies on Magnesium Oxide Reinforced Chitosan Bionanocomposite Incorporated with Clove Oil for Active Food Packaging Application. Int. J. Polym. Mater. 2014, 63, 733-740. [CrossRef]

66. Xu, Y.; Ren, X.; Hanna, M.A. Chitosan/clay nanocomposite film preparation and characterization. J. Appl. Polym. Sci. 2006, 99, 1684-1691. [CrossRef]

67. Lavorgna, M.; Piscitelli, F.; Mangiacapra, P.; Buonocore, G.G. Study of the combined effect of both clay and glycerol plasticizer on the properties of chitosan films. Carbohydr. Polym. 2010, 82, 291-298. [CrossRef]

68. Günister, E.; Pestreli, D.; Ünlü, C.H.; Atıc1, O.; Güngör, N. Synthesis and characterization of chitosan-MMT biocomposite systems. Carbohydr. Polym. 2007, 67, 358-365. [CrossRef]

69. Lewandowska, K.; Sionkowska, A.; Kaczmarek, B.; Furtos, G. Characterization of chitosan composites with various clays. Int. J. Biol. Macromol. 2014, 65, 534-541. [CrossRef]

70. Dias, M.V.; Machado Azevedo, V.; Borges, S.V.; Soares, N.D.F.F.; de Barros Fernandes, R.V.; Marques, J.J.; Medeiros, É.A.A. Development of chitosan/montmorillonite nanocomposites with encapsulated $\alpha$-tocopherol. Food Chem. $2014,165,323-329$. [CrossRef]

71. Hong, S.I.; Lee, J.H.; Bae, H.J.; Koo, S.Y.; Lee, H.S.; Choi, J.H.; Kim, D.H.; Park, S.; Park, H.J. Effect of shear rate on structural, mechanical, and barrier properties of chitosan/montmorillonite nanocomposite film. J. Appl. Polym. Sci. 2009, 119, $2742-2749$. [CrossRef]

72. Abdollahi, M.; Rezaei, M.; Farzi, G. A novel active bionanocomposite film incorporating rosemary essential oil and nanoclay into chitosan. J. Food Eng. 2012, 111, 343-350. [CrossRef]

73. Kasirga, Y.; Oral, A.; Caner, C. Preparation and characterization of chitosan/montmorillonite-K10 nanocomposites films for food packaging applications. Polym. Compos. 2012, 33, 1874-1882. [CrossRef]

74. Giannakas, A.; Grigoriadi, K.; Leontiou, A.; Barkoula, N.M.; Ladavos, A. Preparation, characterization, mechanical and barrier properties investigation of chitosan-clay nanocomposites. Carbohydr. Polym. 2014, 108, 103-111. [CrossRef]

75. Souza, V.G.L.; Pires, J.R.A.; Rodrigues, P.F.; Lopes, A.A.S.; Fernandes, F.M.B.; Duarte, M.P.; Coelhoso, I.M.; Fernando, A.L. Bionanocomposites of chitosan/montmorillonite incorporated with Rosmarinus officinalis essential oil: Development and physical characterization. Food Packag. Shelf Life 2018, 16, 148-156. [CrossRef]

76. Giannakas, A.; Stathopoulou, P.; Tsiamis, G.; Salmas, C. The effect of different preparation methods on the development of chitosan/thyme oil/montmorillonite nanocomposite active packaging films. J. Food Process. Preserv. 2020, 44, e14327. [CrossRef]

77. Potarniche, C.G.; Vuluga, Z.; Donescu, D.; Christiansen, J.D.C.; Eugeniu, V.; Radovici, C.; Serban, S.; Ghiurea, M.; Somoghi, R.; Beckmann, S. Morphology study of layered silicate/chitosan nanohybrids. Surf. Interface Anal. 2011, 44, 200-207. [CrossRef]

78. Gierszewska, M.; Jakubowska, E.; Olewnik-kruszkowska, E. Effect of chemical crosslinking on properties of chitosanmontmorillonite composites. Polym. Test. 2019, 77, 105872. [CrossRef] 
79. Liang, B.; Shu, Y.; Wan, P.; Zhao, H.; Dong, S.; Hao, W. Genipin-enhanced nacre-inspired montmorillonite-chitosan film with superior mechanical and UV-blocking properties. Compos. Sci. Technol. 2019, 182, 107747. [CrossRef]

80. Pires, J.R.A.; Souza, V.G.L.; Fernando, A.L. Comparison of alkaline and ionic liquids pre-treatment applied to residues of perennial crops. Eur. Biomass Conf. Exhib. Proc. 2019, 1460-1463.

81. Ng, H.; Sin, L.T.; Bee, S.; Tee, T.-T.; Rahmat, A.R. Review of Nanocellulose Polymer Composite Characteristics and Challenges. Polym. Plast. Technol. Eng. 2017, 56, 687-731. [CrossRef]

82. Chaichi, M.; Hashemi, M.; Badii, F.; Mohammadi, A. Preparation and characterization of a novel bionanocomposite edible film based on pectin and crystalline nanocellulose. Carbohydr. Polym. 2017, 157, 167-175. [CrossRef]

83. Rong, S.Y.; Mubarak, N.M.; Tanjung, F.A. Structure-property relationship of cellulose nanowhiskers reinforced chitosan biocomposite films. J. Environ. Chem. Eng. 2017, 5, 6132-6136. [CrossRef]

84. Mujtaba, M.; Salaberria, A.M.; Andres, M.A.; Kaya, M.; Gunyakti, A.; Labidi, J. Utilization of flax (Linum usitatissimum) cellulose nanocrystals as reinforcing material for chitosan films. Int. J. Biol. Macromol. 2017, 104, 944-952. [CrossRef] [PubMed]

85. El Achaby, M.; El Miri, N.; Aboulkas, A.; Zahouily, M.; Bilal, E.; Barakat, A.; Solhy, A. Processing and properties of eco-friendly bio-nanocomposite films filled with cellulose nanocrystals from sugarcane bagasse. Int. J. Biol. Macromol. 2017, 96, 340-352. [CrossRef] [PubMed]

86. Xu, K.; Liu, C.; Kang, K.; Zheng, Z.; Wang, S.; Tang, Z.; Yang, W. Isolation of nanocrystalline cellulose from rice straw and preparation of its biocomposites with chitosan: Physicochemical characterization and evaluation of interfacial compatibility. Compos. Sci. Technol. 2018, 154, 8-17. [CrossRef]

87. Qian, S.; Zhang, H.; Yao, W.; Sheng, K. Effects of bamboo cellulose nanowhisker content on the morphology, crystallization, mechanical, and thermal properties of PLA matrix biocomposites. Compos. Part B 2018, 133, 203-209. [CrossRef]

88. Gopi, S.; Amalraj, A.; Jude, S.; Thomas, S.; Guo, Q. Bionanocomposite films based on potato, tapioca starch and chitosan reinforced with cellulose nanofiber isolated from turmeric spent. J. Taiwan Inst. Chem. Eng. 2019, 96, 664-671. [CrossRef]

89. Jacob, J.; Peter, G.; Thomas, S.; Haponiuk, J.T.; Gopi, S. Chitosan and polyvinyl alcohol nanocomposites with cellulose nano fibers from ginger rhizomes and its antimicrobial activities. Int. J. Biol. Macromol. 2019, 129, 370-376. [CrossRef]

90. Kumar, R.; Rai, B.; Kumar, G. A simple approach for the synthesis of cellulose nanofiber reinforced Chitosan/PVP bio nanocomposite film for packaging. J. Polym. Environ. 2019, 27, 2963-2973. [CrossRef]

91. Khan, A.; Khan, R.A.; Salmieri, S.; Le, C.; Riedl, B.; Bouchard, J.; Tan, V.; Kamal, M.R.; Lacroix, M. Mechanical and barrier properties of nanocrystalline cellulose reinforced chitosan based nanocomposite films. Carbohydr. Polym. 2012, 90, 1601-1608. [CrossRef]

92. Dufresne, A. Nanocellulose: A new ageless bionanomaterial. Mater. Today 2013, 16, 220-227. [CrossRef]

93. Bras, J.; Viet, D.; Bruzzese, C.; Dufresne, A. Correlation between stiffness of sheets prepared from cellulose whiskers and nanoparticles dimensions. Carbohydr. Polym. 2011, 84, 211-215. [CrossRef]

94. Siripatrawan, U.; Kaewklin, P. Fabrication and characterization of chitosan-titanium dioxide nanocomposite film as ethylene scavenging and antimicrobial active food packaging. Food Hydrocoll. 2018, 84, 125-134. [CrossRef]

95. Lan, W.; Wang, S.; Zhang, Z.; Liang, X.; Liu, X.; Zhang, J. Development of red apple pomace extract/chitosan-based films reinforced by TiO2 nanoparticles as a multifunctional packaging material. Int. J. Biol. Macromol. 2021, 168, 105-115. [CrossRef]

96. Zhang, X.; Xiao, G.; Wang, Y.; Zhao, Y.; Su, H.; Tan, T. Preparation of chitosan- $\mathrm{TiO}_{2}$ composite film with efficient antimicrobial activities under visible light for food packaging applications. Carbohydr. Polym. 2017, 169, 101-107. [CrossRef]

97. Mallakpour, S.; Madani, M. Effect of Functionalized TiO2 on Mechanical, Thermal and Swelling Properties of Chitosan-Based Nanocomposite Films. Polym. Plast. Technol. Eng. 2015, 54, 1035-1042. [CrossRef]

98. Souza, V.G.L.; Rodrigues, C.; Valente, S.; Pimenta, C.; Pires, J.R.A.; Alves, M.M.; Santos, C.F.; Coelhoso, I.M.; Fernando, A.L.L. Eco-Friendly ZnO/Chitosan Bionanocomposites Films for Packaging of Fresh Poultry Meat. Coatings 2020, 10, 110. [CrossRef]

99. Li, L.; Deng, J.; Deng, H.; Liu, Z.; Xin, L. Synthesis and characterization of chitosan/ZnO nanoparticle composite membranes. Carbohydr. Res. 2010, 345, 994-998. [CrossRef] [PubMed]

100. Mujeeb Rahman, P.; Abdul Mujeeb, V.M.; Muraleedharan, K.; Thomas, S.K. Chitosan/nano ZnO composite films: Enhanced mechanical, antimicrobial and dielectric properties. Arab. J. Chem. 2018, 11, 120-127. [CrossRef]

101. Zhang, X.; Liu, Y.; Yong, H.; Qin, Y.; Liu, J.; Liu, J. Development of multifunctional food packaging films based on chitosan, TiO2 nanoparticles and anthocyanin-rich black plum peel extract. Food Hydrocoll. 2019, 94, 80-92. [CrossRef]

102. Priyadarshi, R.; Singh, Y. Effect of varying filler concentration on zinc oxide nanoparticle embedded chitosan films as potential food packaging material. J. Polym. Environ. 2017, 25, 1087-1098. [CrossRef]

103. De Silva, R.T.; Mantilaka, M.M.M.G.P.G.; Ratnayake, S.P.; Amaratunga, G.A.J.; de Silva, K.M.N. Nano-MgO reinforced chitosan nanocomposites for high performance packaging applications with improved mechanical, thermal and barrier properties. Carbohydr. Polym. 2017, 157, 739-747. [CrossRef]

104. Wang, Y.; Cen, C.; Chen, J.; Fu, L. MgO/carboxymethyl chitosan nanocomposite improves thermal stability, waterproof and antibacterial performance for food packaging. Carbohydr. Polym. 2020, 236, 116078. [CrossRef]

105. Yadav, M.; Yop, K.; Jin, S.; Hui, D. Mechanical properties of Fe3O4/GO/chitosan composites. Compos. Part B 2014, 66, 89-96. [CrossRef]

106. Wang, S.; Shen, L.; Zhang, W.; Tong, Y. Preparation and mechanical properties of chitosan/carbon nanotubes composites. Biomacromolecules 2005, 6, 3067-3072. [CrossRef] 
107. Tang, C.; Chen, N.; Zhang, Q.; Wang, K.; Fu, Q.; Zhang, X. Preparation and properties of chitosan nanocomposites with nanofillers of different dimensions. Polym. Degrad. Stab. 2009, 94, 124-131. [CrossRef]

108. Razavi, R.; Zare, Y.; Yop, K. A model for tensile strength of polymer/carbon nanotubes nanocomposites assuming the percolation of interphase regions. Colloids Surf. A Physicochem. Eng. Asp. 2018, 538, 148-154. [CrossRef]

109. Liu, Y.; Chen, W.; Chang, Y. Preparation and properties of chitosan/carbon nanotube nanocomposites using poly (styrene sulfonic acid)-Modified CNTs. Carbohydr. Polym. 2009, 76, 232-238. [CrossRef]

110. Thai Ong, Y.; Latif, A.; Hussein, S.; Zein, S.; Sudesh, K.; Huat, S. Poly(3-hydroxybutyrate)-functionalised multi-walled carbonnanotubes/chitosan green nanocomposite membranes andtheir application in pervaporation. Sep. Purif. Technol. 2011, 76, 419-427. [CrossRef]

111. Aryaei, A.; Jayatissa, A.H.; Jayasuriya, A.C. Mechanical and biological properties of chitosan/carbon nanotube nanocomposite films. J. Biomed. Mater. Res. 2013, 102, 2704-2712. [CrossRef]

112. Bakhtiari, S.S.E.; Karbasi, S.; Tabrizi, S.A.H.; Ebrahimi-Kahrizsangi, R. Chitosan/MWCNTs composite as bone substitute: Physical, mechanical, bioactivity, and biodegradation evaluation. Polym. Compos. 2019, 40, E1622-E1632. [CrossRef]

113. Wang, J.; Gong, C.; Wen, S.; Liu, H.; Qin, C.; Xiong, C.; Dong, L. A facile approach of fabricating proton exchange membranes by incorporating polydopamine- functionalized carbon nanotubes into chitosan. Int. J. Hydrogen Energy 2019, 44, 6909-6918. [CrossRef]

114. Ke, G.; Guan, W.; Tang, C.; Guan, W.; Zeng, D. Covalent functionalization of multiwalled carbon nanotubes with a low molecular weight chitosan. Biomacromolecules 2007, 8, 322-326. [CrossRef]

115. Iamsamai, C.; Hannongbua, S.; Ruktanonchai, U. The effect of the degree of deacetylation of chitosan on its dispersion of carbon nanotubes. Carbon N. Y. 2010, 48, 25-30. [CrossRef]

116. Bibi, S.; Price, G.J.; Yasin, T.; Nawaz, M. Eco-friendly synthesis and catalytic application of chitosan/gold/carbon nanotube nanocomposite films. RSC Adv. 2016, 6, 60180-60186. [CrossRef]

117. Bibi, S.; Jamil, A.; Yasin, T.; Aftab, M.; Nawaz, M.; Price, G.J. Ultrasound promoted synthesis and properties of chitosan nanocomposites containing carbon nanotubes and silver nanoparticles. Eur. Polym. J. 2018, 105, 297-303. [CrossRef]

118. Rai, S.; Dutta, P.K.; Mehrotra, G.K. Lignin incorporated antimicrobial chitosan film for food packaging application. J. Polym. Mater. 2017, 34, 171-183.

119. Yang, W.; Fortunati, E.; Bertoglio, F.; Owczarek, J.S.; Bruni, G.; Kozanecki, M.; Kenny, J.M.; Torre, L.; Visai, L.; Puglia, D. Polyvinyl alcohol/chitosan hydrogels with enhanced antioxidant and antibacterial properties induced by lignin nanoparticles. Carbohydr. Polym. 2018, 181, 275-284. [CrossRef] [PubMed]

120. Jaganathan, G.; Manivannan, K.; Lakshmanan, S.; Sithique, M.A. Fabrication and characterization of Artocarpus heterophyllus waste derived lignin added chitosan biocomposites for wound dressing application. Sustain. Chem. Pharm. 2018, 10, 27-32. [CrossRef]

121. Sohni, S.; Hashim, R.; Nidaullah, H.; Lamaming, J.; Sulaiman, O. Chitosan/nano-lignin based composite as a new sorbent for enhanced removal of dye pollution from aqueous solutions. Int. J. Biol. Macromol. 2019, 132, 1304-1317. [CrossRef] [PubMed] 